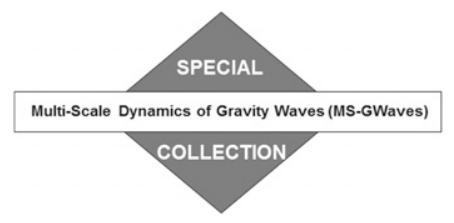

\title{
əSeasonal Cycle of Gravity Wave Potential Energy Densities from Lidar and Satellite Observations at $54^{\circ}$ and $69^{\circ} \mathrm{N}$
}

\author{
Irina Strelnikova, ${ }^{\mathrm{a}}$ MArwa Almowafy, ${ }^{\mathrm{a}}$ Gerd Baumgarten,,${ }^{\mathrm{a}}$ KATHrin BAumgarten, ${ }^{\mathrm{a}}$ MANFred ERN, \\ MiCHAEL GERDING, ${ }^{\text {a }}$ AND FRANZ-JOSEF LÜBKEN ${ }^{\mathrm{a}}$ \\ ${ }^{a}$ Leibniz Institute of Atmospheric Physics e.V., Rostock University, Kühlungsborn, Germany \\ ${ }^{\mathrm{b}}$ Stratosphäre (IEK-7), Institut für Energie- und Klimaforschung, Forschungszentrum Jülich, Jülich, Germany
}

(Manuscript received 18 August 2020, in final form 21 December 2020)

\begin{abstract}
We present gravity wave climatologies based on 7 years (2012-18) of lidar and Sounding of the Atmosphere using Broadband Emission Radiometry (SABER) temperatures and reanalysis data at $54^{\circ}$ and $69^{\circ} \mathrm{N}$ in the altitude range 30-70 km. We use 9452 (5044) h of lidar observations at Kühlungsborn [Arctic Lidar Observatory for Middle Atmosphere Research (ALOMAR)]. Filtering according to vertical wavelength $\left(\lambda_{z}<15 \mathrm{~km}\right)$ or period $(\tau<8 \mathrm{~h})$ is applied. Gravity wave potential energy densities (GWPED) per unit volume $\left(E_{\mathrm{pV}}\right)$ and per unit mass $\left(E_{\mathrm{pm}}\right)$ are derived. GWPED from reanalysis are smaller compared to lidar. The difference increases with altitude in winter and reaches almost two orders of magnitude around $70 \mathrm{~km}$. A seasonal cycle of $E_{\mathrm{pV}}$ with maximum values in winter is present at both stations in nearly all lidar and SABER measurements and in reanalysis data. For SABER and for lidar (with $\lambda<15 \mathrm{~km}$ ) the winter/summer ratios are a factor of $\sim 2-4$, but are significantly smaller for lidar with $\tau<8 \mathrm{~h}$. The winter/summer ratios are nearly identical at both stations and are significantly larger for $E_{\mathrm{pm}}$ compared to $E_{\mathrm{pV}}$. Lidar and SABER observations show that $E_{\mathrm{pV}}$ is larger by a factor of $\sim 2$ at Kühlungsborn compared to ALOMAR, independent of season and altitude. Comparison with mean background winds shows that simple scenarios regarding GW filtering, etc., cannot explain the Kühlungsborn-ALOMAR differences. The value of $E_{\mathrm{pV}}$ decreases with altitude in nearly all cases. Corresponding $E_{\mathrm{pV}}$-scale heights from lidar are generally larger in winter compared to summer. Above $\sim 55 \mathrm{~km}, E_{\mathrm{pv}}$ in summer is almost constant with altitude at both stations. The winter-summer difference of $E_{\mathrm{pV}}$ scale heights is much smaller or absent in SABER and in reanalysis data.
\end{abstract}

KEYWORDS: Gravity waves; Inertia-gravity waves; Lidars/Lidar observations; Satellite observations; Reanalysis data

\section{Introduction}

It is commonly accepted that gravity waves $(\mathrm{GW})$ play a crucial role in middle-atmospheric circulation, structure, variability, and composition. GW are mainly generated in the troposphere/lower stratosphere by dynamical processes such as convection, wind shears, jet streams, wave-wave interactions, and flows over orographic structures. Upward-propagating GW grow in amplitude due to the exponential decrease of atmospheric air density. During propagation, GW can lose energy and momentum which is referred to as GW breakdown. The energy and momentum lost by GW is deposited in the background flow

๑ Denotes content that is immediately available upon publication as open access.

\begin{abstract}
Almowafy's current affiliation: Astronomy and Meteorology Department, Faculty of Science, Cairo University, Giza, Egypt.

K. Baumgarten's current affiliation: Fraunhofer Institute for Computer Graphics Research (IGD), Rostock, Germany.
\end{abstract}

Corresponding author: Irina Strelnikova, strelnikova@iapkborn.de which, for example, leads to a mesospheric residual circulation from pole to pole and creates a cold summer mesopause at high latitudes (e.g., Lindzen 1981; Holton 1982; Hitchman et al. 1989; Lübken 1999; Fritts and Alexander 2003; Zhao et al. 2017). It is therefore important to understand the morphology of the GW field and its variation with season and latitude.

Different measurement techniques like satellites (e.g., Hoffmann et al. 2013; Ern et al. 2018), lidars (e.g., Rauthe et al. 2008; Chu et al. 2018), radars (e.g., Hoffmann et al. 2010; Alexander and Murphy 2015; Stober et al. 2021), or balloons (e.g., Allen and Vincent 1995; Hertzog et al. 2008) and rockets (Hirota 1984; Eckermann et al. 1995; Wang et al. 2006) provide detailed information about GW activity in the lower, middle, and upper atmosphere. These techniques cover different height ranges and resolve different fractions of GW spectra in time or space. However, none of them can provide a complete detailed picture. Each measurement technique has its own unique advantages which may enlighten some GW features not seen by other methods. For example, lidars can provide quasicontinuous measurements with high resolution both in time and altitude, thereby allowing for detailed studies of smallscale GW properties. On the other hand, they usually do not provide information about the horizontal distribution of GW.

Unfortunately, it is rather difficult to compare different observations quantitatively. The reason for this is that GW 
parameters commonly calculated from measurements are based on deviations from background temperature, density, or winds. Thus, different instruments with different noise level, resolution, temporal and spatial coverage, and background definition will cover different parts of the GW spectrum. A standardized framework for obtaining gravity wave parameters is required to homogenize different studies and to make full use of the information provided by the available measurements (Ehard et al. 2014). Since such framework currently does not exist, global information about the variability of gravity wave activity can be obtained only by satellite observations, however, again with instrumental constraints. More information about observational filters of satellite observations can be found in the literature (see, e.g., Preusse et al. 2008; Alexander et al. 2010; Ern et al. 2018). On the other hand, different instruments covering different spectral windows of the GW spectrum yield complementary observations. The combination of different instruments, e.g., lidar and satellite, usually provide a more detailed picture of $\mathrm{GW}$ parameters (Llamedo et al. 2019).

In practice, it is often convenient to have an average reference GW field being representative for a certain latitude and season. Such averaged GW fields, also called climatologies, were published earlier for different locations and altitudes (e.g., Hirota 1984; Tsuda et al. 1994; Whiteway and Carswell 1995; Eckermann 1995b; Rauthe et al. 2008; Baumgarten et al. 2017, hereafter referred to as KB17; Chu et al. 2018; Llamedo et al. 2019). For example, based on one year of lidar observations (1991-92) near Toronto $\left(44^{\circ} \mathrm{N}, 80^{\circ} \mathrm{W}\right)$, Whiteway and Carswell (1995) reported that the potential energy in the 35 to $50 \mathrm{~km}$ altitude region varied considerably from day to day and seasonally with a winter maximum $\left(\sim 15 \mathrm{~J} \mathrm{~kg}^{-1}\right)$ and summer minimum $\left(\sim 6 \mathrm{~J} \mathrm{~kg}^{-1}\right)$. Hirota (1984) used meteorological rocket data to obtain the seasonal variation in gravity wave activity in the 30 to $60 \mathrm{~km}$ altitude region at a wide range of latitudes. They found an annual cycle with a winter maximum and summer minimum at high and middle latitudes but a semiannual cycle at low latitudes with maxima at the equinoxes. A substantial day-to-day variability was also apparent in these rocket data. Various other measurements generally also demonstrated that the seasonal variation of GW activity in the upper stratosphere and lower mesosphere is dominated by a maximum in winter and a minimum in summer (e.g., Wilson et al. 1991; Rauthe et al. 2008; KB17; Hoffmann et al. 2017; Chu et al. 2018; Llamedo et al. 2019). Some studies also showed a semiannual variation, however, mainly in the upper mesosphere/lower thermosphere (e.g., Tsuda et al. 1994; Mitchell and Beldon 2009; Hoffmann et al. 2010; Chen et al. 2019).

In this study we present the first seasonal cycle of GW potential energy densities (GWPED) in the altitude range 30 to $70 \mathrm{~km}$ derived from temperature measurements during the years 2012-18 performed at the Arctic Lidar Observatory for Middle Atmosphere Research (ALOMAR) located in Andenes, northern Norway $\left(69^{\circ} \mathrm{N}, 16^{\circ} \mathrm{E}\right)$. We compare with the GWPED seasonal cycle from temperature observations in Kühlungsborn, Germany $\left(54^{\circ} \mathrm{N}, 12^{\circ} \mathrm{E}\right)$ in the same altitude range and during the same time period (cf. KB17). Both lidars are daytime capable so that they can be operated during the whole day if weather conditions permit. This is essential for measuring in polar regions where the Sun is permanently above the horizon during the summer months. We also use satellitebased temperature data from the Sounding of the Atmosphere using Broadband Emission Radiometry (SABER) for comparison with the lidar GW measurements at both locations. Finally, our observations are compared to two widely used reanalysis datasets, namely, NASA Modern-Era Retrospective Analysis for Research and Applications version 2 (MERRA-2) and the fifth generation of ECMWF atmospheric reanalysis of the global climate (ERA5).

The paper is structured as follows. In section 2 the lidar instruments and the observations available at ALOMAR and Kühlungsborn are described, as well as the database from the SABER satellite and the MERRA-2 and ERA5 datasets. In section 3 we present details of the data analysis both for lidar and satellite observations. The main results are presented in sections 4 and 5 , followed by a discussion (section 6) and concluding remarks in section 7 .

\section{Instrumentation}

\section{a. ALOMAR lidar}

ALOMAR is located in northern Norway $\left(69.3^{\circ} \mathrm{N}, 16.0^{\circ} \mathrm{E}\right)$, close to the Scandinavian mountains. A Rayleigh-Mie-Raman (RMR) lidar has been in operation at ALOMAR since 1994. The lidar provides observations of temperatures, winds, aerosols, and noctilucent clouds during day- and nighttime (e.g., von Zahn et al. 2000; Schöch et al. 2008; Fiedler et al. 2011; Baumgarten et al. 2015). Approximately $16000 \mathrm{~h}$ of temperature measurements have been recorded since the start of operation. In this manuscript $5044 \mathrm{~h}$ are being used. The lidar consists of two independent power lasers, two receiving telescopes (typically pointing in different directions), and one detection system. The lasers are firing alternatingly to record the data by the detection system. The raw data are stored with a resolution of $33 \mathrm{~s}$ and $50 \mathrm{~m}$. They are integrated in temporal and spatial ranges of $5 \mathrm{~min}$ and $150 \mathrm{~m}$ altitude, respectively, separately for each of the two telescopes (Baumgarten et al. 2015). The data are further smoothed using a running mean with a width of $2 \mathrm{~h}$ and $1 \mathrm{~km}$. Backscattered signals at wavelengths of 532 and $355 \mathrm{~nm}$ are used separately to calculate temperature profiles using hydrostatic integration (Hauchecorne and Chanin 1980). Temperatures from both wavelengths and from both telescopes are then combined by calculating the error weighted mean. We have studied the temperature profiles individually for both telescopes which are covering the atmosphere separated horizontally by up to $50 \mathrm{~km}$. No significant difference between the two telescopes was found which is presumably a consequence of the long averaging time. Temperature profiles are available up to $90 \mathrm{~km}$ during night and $70 \mathrm{~km}$ during day. Data below $30 \mathrm{~km}$ are not used in this study due to the sporadic presence of stratospheric aerosols at these altitudes which introduces substantial uncertainties in deriving temperatures (Langenbach et al. 2019).

\section{b. Kühlungsborn lidar}

The daylight-capable Rayleigh-Mie-Raman lidar has been installed in Kühlungsborn $\left(54.1^{\circ} \mathrm{N}, 11.8^{\circ} \mathrm{E}\right)$ in 2009 and is 
operated regularly since summer 2010 (Gerding et al. 2016). About $10800 \mathrm{~h}$ of measurements have been recorded so far. In this paper $9452 \mathrm{~h}$ are being used. Similar to the ALOMAR lidar we make use of a flashlamp pumped, injection-seeded neodymium-doped yttrium-aluminum-garnet (Nd:YAG) laser, but transmit only the second harmonic output at $532 \mathrm{~nm}$. The solar background during day is suppressed applying two etalons with full width at half maximum (FWHM) of 4 and $4.5 \mathrm{pm}$, in combination with a $130 \mathrm{pm}$ interference filter. A narrow field of view of only $\sim 60 \mu \mathrm{rad}$ is applied together with an active beam stabilization on a single-pulse basis. The daylight setup is used also during nighttime to achieve a continuous data stream without technical changes. The raw data are integrated for $2 \mathrm{~h}$ with $15 \mathrm{~min}$ oversampling, using two detectors with different sensitivities above and below $37 \mathrm{~km}$. Temperature profiles are calculated applying hydrostatic integration. The initial altitude resolution for temperatures is $195 \mathrm{~m}$, which is later downsampled to a $1 \mathrm{~km}$ grid. Finally, the data of both detectors are combined to a single temperature profile. Typically, the data cover a similar altitude range as the ALOMAR lidar, namely, up to at least $70 \mathrm{~km}$.

Minor differences between the two lidars in the choice of the start temperatures [taken from NRLMSISE-00 (Picone et al. 2002) or CIRA-86 (Fleming et al. 1990)] and start altitudes for the hydrostatic integrations have only little effects on the results presented here, because this paper mainly deals with temperature fluctuations within $24 \mathrm{~h}$, but not with absolute temperatures.

\section{c. SABER satellite instrument}

The SABER instrument is an infrared emission limb sounder covering the upper troposphere, stratosphere, mesosphere, and lower thermosphere. It is one of four instruments on NASA's Thermosphere, Ionosphere, Mesosphere Energetics and Dynamics (TIMED) satellite (e.g., Mlynczak 1997; Russell et al. 1999; Yee et al. 2003). SABER observations started in January 2002 and are still ongoing. SABER temperature observations cover altitudes from below $20 \mathrm{~km}$ to well above $90 \mathrm{~km}$ with nearly global coverage. The TIMED satellite performs yaw cycles such that SABER alternates between a southward and a northward viewing geometry every $\sim 60$ days. For southward viewing the latitude coverage is about $80^{\circ} \mathrm{S}$ to $52^{\circ} \mathrm{N}$, somewhat depending on altitude, and about $52^{\circ} \mathrm{S}$ to $80^{\circ} \mathrm{N}$ for northward viewing. Latitudes between $52^{\circ} \mathrm{S}$ and $52^{\circ} \mathrm{N}$ are observed continuously (Remsberg et al. 2008). The vertical resolution of SABER temperature profiles is about $2 \mathrm{~km}$ (e.g., Ern et al. 2018, and references therein), which is very close to the vertical field of view of the instrument (Remsberg et al. 2008). SABER temperature observations have repeatedly been used for deriving amplitudes, potential energy densities, as well as absolute momentum fluxes of gravity waves. In this study we use time series of gravity wave potential energy densities for comparison with lidar data. Details on the procedure to extract gravity waves from SABER temperatures, as well as details about the gravity wave datasets used in this study, are given in section $3 b$.

\section{d. Reanalysis}

For comparison we also use the NASA MERRA-2 (Fujiwara et al. 2017) and ERA5 (Hersbach et al. 2020). Both reanalysis datasets are available on model levels covering altitudes from the ground to about $80 \mathrm{~km}$. Data were extracted at the two locations of the lidar instruments by linear interpolation. MERRA-2 provides data on 72 pressure levels and a horizontal resolution of about $50 \mathrm{~km}$ with a time step of $3 \mathrm{~h}$ (Global Modeling and Assimilation Office 2015). In global models, sponge layers are commonly applied near the upper boundary to reduce unrealistic reflection of vertically propagating waves from the model top. MERRA-2 implements sponge layers above $\sim 0.24 \mathrm{hPa}$ by increasing the horizontal divergence damping coefficient [see Fujiwara et al. (2017) for more details].

ERA5 data are available on 137 levels from the ground to $0.01 \mathrm{hPa}$ with a horizontal resolution of about $30 \mathrm{~km}$ and a time step of $1 \mathrm{~h}$ (Copernicus Climate Change Service 2017). Sponge layers in ERA5 are applied above $10 \mathrm{hPa}$ by adding an additional function to the horizontal diffusion terms, the strength of which varies with wavenumber and model level (Polichtchouk et al. 2017; Kawatani et al. 2020).

\section{Methodology and data description}

\section{a. Lidar dataset}

We process the lidar data from ALOMAR $\left(69^{\circ} \mathrm{N}\right)$ and Kühlungsborn $\left(54^{\circ} \mathrm{N}\right)$ by applying the same analysis technique to avoid any biases caused by differences in data processing. Soundings with at least $6 \mathrm{~h}$ of continuous measurements were selected, shorter time series are ignored. Measurements that last for more than one day are divided into $24 \mathrm{~h}$ segments as in KB17. Within the period from 2012 to 2018 a total number of 5044 and $9452 \mathrm{~h}$ have been used from the ALOMAR and Kühlungsborn lidars, respectively. A detailed list of the number of soundings and number of measurement hours are provided in Tables 1 and 2. On average more than $500 \mathrm{~h}$ of measurements are available per month, except for December, where the coverage is less than $100 \mathrm{~h}$ at both stations. We note that observations are not evenly distributed over the year.

By averaging the data over $2 \mathrm{~h}$ and $1 \mathrm{~km}$ the effects of small-scale processes like turbulence are eliminated and instrumental noise is suppressed. Temperature errors are derived assuming Poisson noise of the recorded signals and by applying error propagation through all data processing steps. Data points with errors larger than $10 \mathrm{~K}$ are excluded from further processing.

Lidar temperatures contain tidal and GW fluctuations on top of a background that contains only slow variations, such as the seasonal cycle or planetary waves. Since we use data blocks shorter than $24 \mathrm{~h}$, the contribution from planetary waves (PW) is removed because they usually have periods of at least a few days (e.g., Kishore et al. 2006).

Figure 1 shows examples of temperature measurements at ALOMAR and Kühlungsborn. Each of these examples contains nearly continuous time series of more than three days (except Kühlungsborn in January, where only 2 days are shown). Remarkable temperature variations are seen throughout the observations in January. For example, at ALOMAR the stratopause temporarily shows a double maximum at $40 \mathrm{~km}$ and 
TABLE 1. Number of soundings longer than $6 \mathrm{~h}$ for the ALOMAR lidar (A) and the Kühlungsborn lidar (K).

\begin{tabular}{|c|c|c|c|c|c|c|c|c|c|c|c|c|c|c|}
\hline Year & Station & Jan & Feb & Mar & Apr & May & Jun & Jul & Aug & Sep & Oct & Nov & Dec & $\Sigma$ \\
\hline \multirow[t]{2}{*}{2012} & A & 6 & 0 & 1 & 4 & 0 & 7 & 2 & 5 & 1 & 0 & 1 & 2 & 29 \\
\hline & $\mathrm{K}$ & 6 & 4 & 12 & 3 & 13 & 11 & 10 & 10 & 4 & 5 & 0 & 0 & 78 \\
\hline \multirow[t]{2}{*}{2013} & A & 2 & 6 & 2 & 1 & 4 & 9 & 8 & 6 & 8 & 0 & 0 & 2 & 48 \\
\hline & $\mathrm{K}$ & 0 & 0 & 7 & 8 & 7 & 15 & 20 & 11 & 4 & 5 & 4 & 0 & 81 \\
\hline \multirow[t]{2}{*}{2014} & A & 14 & 4 & 2 & 2 & 5 & 4 & 14 & 3 & 0 & 0 & 0 & 0 & 48 \\
\hline & $\mathrm{K}$ & 0 & 2 & 8 & 1 & 7 & 18 & 20 & 5 & 12 & 0 & 0 & 0 & 73 \\
\hline \multirow[t]{2}{*}{2015} & A & 5 & 0 & 4 & 1 & 4 & 3 & 5 & 8 & 4 & 5 & 0 & 0 & 39 \\
\hline & $\mathrm{K}$ & 0 & 3 & 5 & 5 & 2 & 14 & 16 & 14 & 8 & 7 & 2 & 0 & 76 \\
\hline \multirow[t]{2}{*}{2016} & A & 8 & 7 & 3 & 2 & 6 & 4 & 5 & 8 & 5 & 5 & 4 & 0 & 57 \\
\hline & $\mathrm{K}$ & 0 & 2 & 4 & 7 & 15 & 19 & 15 & 11 & 17 & 0 & 3 & 2 & 95 \\
\hline \multirow[t]{2}{*}{2017} & A & 3 & 9 & 5 & 1 & 4 & 9 & 5 & 3 & 11 & 1 & 0 & 0 & 51 \\
\hline & $\mathrm{K}$ & 4 & 4 & 4 & 4 & 10 & 15 & 11 & 9 & 2 & 3 & 2 & 1 & 69 \\
\hline \multirow[t]{2}{*}{2018} & A & 5 & 20 & 5 & 5 & 4 & 1 & 9 & 1 & 0 & 0 & 0 & 0 & 50 \\
\hline & $\mathrm{K}$ & 4 & 6 & 5 & 10 & 22 & 15 & 24 & 8 & 10 & 11 & 5 & 3 & 123 \\
\hline \multirow[t]{2}{*}{ Total } & A & 43 & 46 & 22 & 16 & 27 & 37 & 48 & 34 & 29 & 11 & 5 & 4 & 322 \\
\hline & $\mathrm{K}$ & 14 & 21 & 45 & 38 & 76 & 107 & 116 & 68 & 57 & 31 & 16 & 6 & 595 \\
\hline
\end{tabular}

45-50 km. An abrupt change of temperature occurs $\sim 10 \mathrm{~km}$ higher, where temperatures drop to $190 \mathrm{~K}$ around $60 \mathrm{~km}$. At Kühlungsborn a single maximum occurs at around $45 \mathrm{~km}$ and successive cold and warm regions of short duration $(<4 \mathrm{~h})$ are observed in the lower mesosphere. In contrast, temperatures show less variability in August compared to January at both stations.

\section{1) DERIVING GRAVITY WAVE PERTURBATIONS FROM RAW TEMPERATURES}

To extract temperature fluctuations due to $\mathrm{GW}$ from lidar observations, the atmospheric background temperature has to be removed. This background consists of a mean temperature profile and a superposition of larger-scale waves, such as PW and tides. Different techniques have been developed to derive this background (e.g., Rauthe et al. 2008; Ehard et al. 2015; KB17; Cai et al. 2017; Chu et al. 2018; Baumgarten and Stober 2019). The easiest and widely applied method for lidar observations is to use a temporal mean temperature profile (e.g., Gardner et al. 1989; Rauthe et al. 2008; Ehard et al. 2014). In this case the mean temperature profile obviously depends on the averaging time. For example, when subtracting the mean over $24 \mathrm{~h}$, fluctuations still contain contributions from periods of several hours (e.g., from semidiurnal tides) whereas these fluctuations are largely removed when nighttime observations of approximately $5 \mathrm{~h}$ duration are being used (e.g., Rauthe et al. 2008). Subtracting a mean profile will also remove any stationary waves thereby underestimating the overall GW activity, because mountain waves will be removed too. Furthermore, semistationary features such as a double-stratopause in Fig. 1a are also removed (e.g., Llamedo et al. 2019).

Various other methods have been developed to separate fluctuations due to gravity waves from the background. For example, Chu et al. (2018) applied a sixth-order Butterworth high-pass filter to remove waves with periods larger than $11 \mathrm{~h}$

TABLE 2. Measurement time (in $\mathrm{h}$ month $^{-1}$ ) for the ALOMAR lidar (A) and the Kühlungsborn lidar (K).

\begin{tabular}{|c|c|c|c|c|c|c|c|c|c|c|c|c|c|c|}
\hline Year & Station & $\mathrm{J}$ & $\mathrm{F}$ & M & A & M & $\mathrm{J}$ & $\mathrm{J}$ & A & $S$ & $\mathrm{O}$ & $\mathrm{N}$ & $\mathrm{D}$ & $\Sigma$ \\
\hline \multirow[t]{2}{*}{2012} & A & 115 & 0 & 11 & 53 & 0 & 87 & 28 & 80 & 7 & 0 & 7 & 20 & 408 \\
\hline & $\mathrm{K}$ & 104 & 45 & 152.5 & 46 & 204 & 126.5 & 181 & 149 & 38.5 & 53 & 0 & 0 & 1099.5 \\
\hline \multirow[t]{2}{*}{2013} & A & 17 & 74 & 39 & 12 & 55 & 157 & 119 & 79 & 105 & 0 & 0 & 44 & 701 \\
\hline & $\mathrm{K}$ & 0 & 0 & 109 & 116 & 98 & 225.5 & 334.5 & 189.5 & 74 & 95.5 & 61 & 0 & 1303 \\
\hline \multirow[t]{2}{*}{2014} & A & 267 & 60 & 21 & 21 & 63 & 79 & 287 & 46 & 0 & 0 & 0 & 0 & 844 \\
\hline & $\mathrm{K}$ & 0 & 33 & 142 & 20 & 107.5 & 269 & 347 & 73 & 208 & 0 & 0 & 0 & 1200 \\
\hline \multirow[t]{2}{*}{2015} & A & 112 & 0 & 77 & 7 & 46 & 30 & 54 & 168 & 51 & 106 & 0 & 0 & 651 \\
\hline & $\mathrm{K}$ & 0 & 39.5 & 76.5 & 61 & 16 & 197.5 & 204 & 254 & 108 & 97 & 17 & 0 & 1070 \\
\hline \multirow[t]{2}{*}{2016} & A & 160 & 68 & 40 & 20 & 85 & 48 & 70 & 128 & 61 & 59 & 48 & 0 & 787 \\
\hline & $\mathrm{K}$ & 0 & 28 & 68 & 87 & 290 & 287 & 179.5 & 155 & 308 & 0 & 52 & 35 & 1489.5 \\
\hline \multirow[t]{2}{*}{2017} & A & 40 & 197 & 92 & 8 & 46 & 180 & 45 & 45 & 129 & 8 & 0 & 0 & 790 \\
\hline & $\mathrm{K}$ & 70.5 & 71 & 84 & 46.5 & 139 & 222 & 148.5 & 108 & 25 & 49 & 23 & 7.5 & 994 \\
\hline \multirow[t]{2}{*}{2018} & A & 87 & 403 & 69 & 49 & 53 & 9 & 176 & 17 & 0 & 0 & 0 & 0 & 863 \\
\hline & $\mathrm{K}$ & 61.5 & 117 & 70 & 159 & 444 & 256.5 & 424 & 150.5 & 176 & 212 & 85 & 37 & 2192 \\
\hline \multirow[t]{2}{*}{ Total } & A & 798 & 802 & 349 & 170 & 348 & 590 & 779 & 563 & 353 & 173 & 55 & 64 & 5044 \\
\hline & $\mathrm{K}$ & 236 & 334 & 702 & 535 & 1299 & 1484 & 1818.5 & 1079 & 937 & 506.5 & 238 & 80 & 9348.5 \\
\hline
\end{tabular}



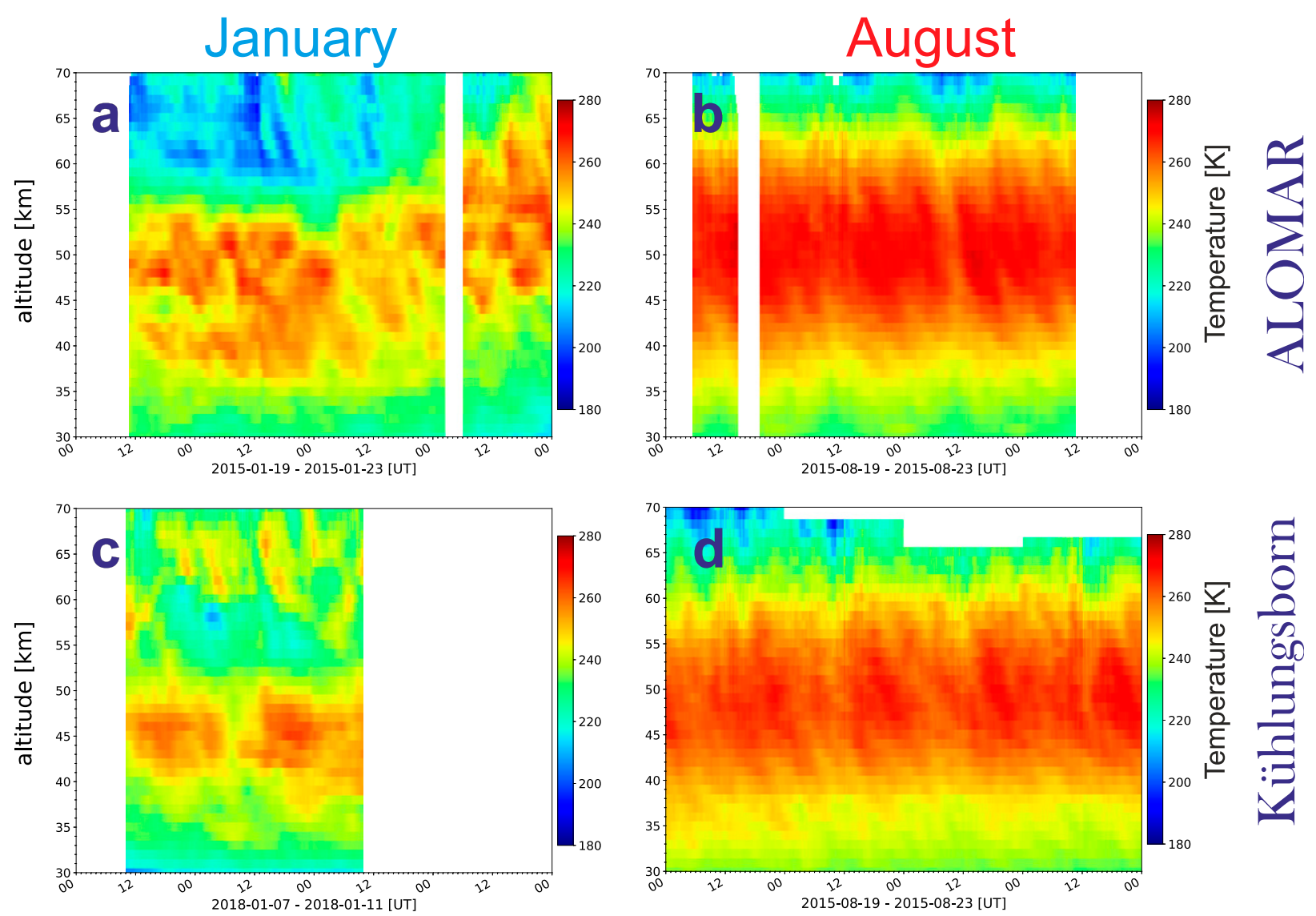

FIG. 1. Examples of time-height cross sections of temperatures measured by lidars in (left) January and (right) August at (top) ALOMAR and (bottom) Kühlungsborn.

and vertical wavelengths larger than $30 \mathrm{~km}$. Cai et al. (2017) applied filtering in the time domain where waves with periods of $4,8,12$, and $24 \mathrm{~h}$ were attributed to the background, and the remaining fluctuations to GW. Baumgarten and Stober (2019) used an adaptive spectral filter for lidar measurements, former developed for radar measurements, which takes an intermittency of tides into account. Other studies used a sliding polynomial fitting procedure (Duck et al. 2001; Alexander et al. 2011; Kaifler et al. 2015). Recently, Ehard et al. (2015) evaluated the most common filtering methods applied to lidar observations by using synthetic data. They concluded that the Butterworth filter performs best if gravity waves over a wide range of periods are to be extracted from lidar temperature measurements. The "running mean" method described in Ehard et al. (2015) gave reliable results if gravity waves with short periods are to be analyzed.

Since the purpose of this study is to compare GWPED measured at two different locations, we precisely repeated the procedure applied for Kühlungsborn data in KB17 to the observations at ALOMAR. We define segments with time lengths between 6 and $24 \mathrm{~h}$. Then the temporal mean is subtracted. The results are called "unfiltered data." By applying a high-pass filter in altitude or time, temperature perturbations with fixed vertical wavelength cutoff altitude or fixed frequency cutoff are retrieved
(Eckermann et al. 1995; Tsuda et al. 2000; Ehard et al. 2015). In more detail we applied a fifth-order Butterworth filter with a cutoff wavelength of $\lambda_{z}=15 \mathrm{~km}$ or a cutoff period of $\tau=8 \mathrm{~h}$. The choice of $\lambda_{z}=15 \mathrm{~km}$ is to assure that semidiurnal tides which have vertical wavelengths of 20 to $100 \mathrm{~km}$ are removed (e.g., Davis et al. 2013). Furthermore, a cutoff period of $\tau=8 \mathrm{~h}$ is sufficient to suppress even the terdiurnal tide. Figure 2 shows a schematic illustration of the difference between vertical and temporal filtering and the particular spectral coverage. The vertically filtered data $\left(\lambda_{z}<15 \mathrm{~km}\right)$ are also called "small (vertical) wavelengths," and the temporally filtered data $(\tau<8 \mathrm{~h})$ are called "small periods" in this paper. In a former paper we have also applied both spatial and temporal filtering simultaneously (Strelnikova et al. 2020) but this is not done here to be compatible with the data processing procedure used in KB17.

Figure 3 shows temperature fluctuations attributed to GW with $\lambda_{z}<15 \mathrm{~km}$ from ALOMAR and Kühlungsborn derived from the temperature fields shown in Fig. 1. At both stations GW signatures are rather different in January compared to August in terms of structure, amplitude, and phase propagation. Fluctuations are considerably larger in winter. In summer, phase lines of a single GW (marked by dashed lines) extend over a larger height range compared to winter. GW 


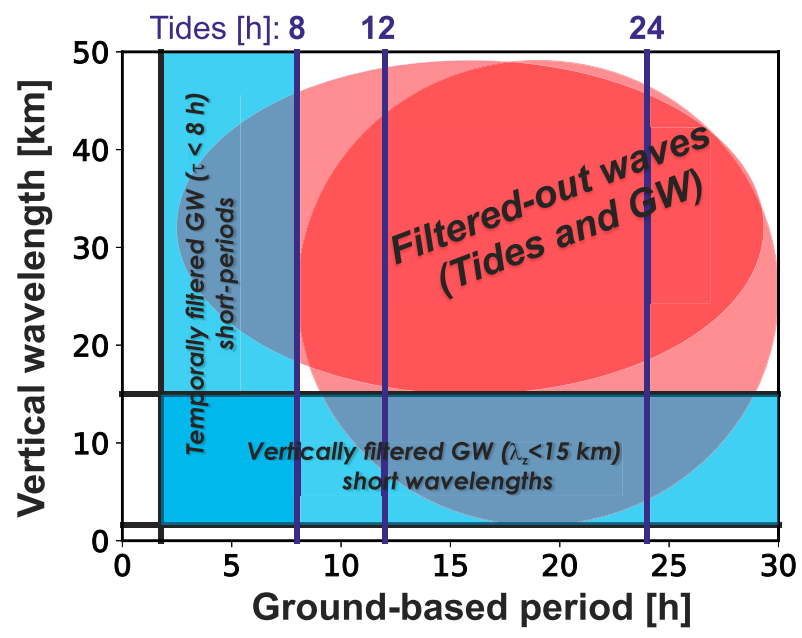

FIG. 2. Schematic illustration of the difference between vertical and temporal filtering. Blue filling represents that part of the data being selected in this study. The red ovals show regions excluded by vertical or temporal filtering. Unfiltered data contain periods from 1 to $24 \mathrm{~h}$ and vertical wavelengths from 1 to $40 \mathrm{~km}$.

with upward phase progression are also present occasionally (green dashed lines and negative slopes) but more so in winter than in summer (in summer above $50 \mathrm{~km}$ only). Generally speaking, the wave field in summer seems to be dominated by few quasi-monochromatic waves, whereas in winter an ensemble of waves propagating in different directions with different phase speeds is present. When comparing the two locations for the same months, no obvious differences are detectable.

\section{2) GRAVITY WAVE POTENTIAL ENERGY DENSITIES}

A widely used physical quantity characterizing GW activity based on temperature fluctuations is the GWPED. There are two forms commonly used, namely, potential energy density per unit mass and per unit volume (see, e.g., Nappo 2002; Gill 1982):

$$
\begin{aligned}
& E_{\mathrm{pm}}=\frac{1}{2} \frac{g^{2}}{N^{2}} \overline{\left(\frac{T^{\prime}}{T_{0}}\right)^{2}} \\
& E_{\mathrm{pV}}=E_{\mathrm{pm}} \bar{\rho}=\frac{1}{2} \frac{g^{2}}{N^{2}} \overline{\left(\frac{T^{\prime}}{T_{0}}\right)^{2}} \bar{\rho} .
\end{aligned}
$$

Here $g$ is gravitational acceleration, $T^{\prime}$ and $T_{0}$ are residual and background temperatures obtained by the three methods as described in the previous section, $\bar{\rho}$ is the daily average atmospheric density profile taken from NRLMSISE-00 (Picone et al. 2002), and $N$ is the buoyancy (Brunt-Väisälä) frequency derived from measured background temperatures. The overbar denotes a temporal average, which is done over the duration of the measured segment. Usually, temperature fluctuations due to gravity waves increase with altitude because of the decrease of background density. This leads to an increase of $E_{\mathrm{pm}}$ with altitude, whereas $E_{\mathrm{pV}}$ is constant with height for undisturbed $\mathrm{GW}$ propagation at constant winds. We derive potential energy densities for unfiltered as well as vertically and temporally filtered temperatures for all individual months as well as mean values for summer (June-August) and winter (December-February).

\section{b. SABER data}

SABER temperatures are analyzed employing algorithms described in the literature (Preusse et al. 2002; Ern et al. 2011, 2018). To isolate gravity waves from observations, the largescale background temperature has to be estimated for each temperature profile. For this purpose, 2D spectra in longitude and time are calculated in a set of overlapping 31 day time windows for a set of fixed latitudes and altitudes. From these zonal wavenumber-frequency spectra, the contribution of global-scale waves is reconstructed at the location and time of each observation in every vertical temperature profile observed by SABER. Temperature fluctuations due to gravity waves are obtained by subtracting this contribution of globalscale waves, as well as an estimate of zonally averaged temperatures. This approach removes global-scale waves of zonal wavenumbers 1-6 and waves with periods longer than 1-2 days. Further, we make use of the fact that satellites, measuring at fixed local solar times, observe tides as quasi-stationary wave patterns if ascending (satellite is flying northward) and descending (satellite is flying southward) parts of the orbit are treated separately. All tidal components which appear as stationary planetary waves up to zonal wavenumber 4 (at a fixed given local solar time) are thereby removed. This includes diurnal tides, semidiurnal tides, terdiurnal tides, etc. (Trinh et al. 2018). In addition, the altitude profiles are low-pass filtered to remove very long vertical wavelengths. The resulting residual temperatures are considered to be due to gravity waves. Overall, the SABER gravity wave dataset used in this paper contains gravity waves with horizontal wavelengths larger than about $100-200 \mathrm{~km}$, vertical wavelengths in the range $4-25 \mathrm{~km}$ and intrinsic periods longer than $1-2 \mathrm{~h}$ [an approximate sensitivity function is given in Ern et al. (2018)]. We use Eq. (2) to calculate $E_{\mathrm{pV}}$ based on SABER background temperatures and SABER gravity wave temperature variances.

SABER "local" data presented in this study are gridded for the two specific locations of Kühlungsborn and ALOMAR. For Kühlungsborn, a longitude bin of $5^{\circ} \mathrm{W}-25^{\circ} \mathrm{E}$ and a latitude bin of $48^{\circ}-60^{\circ} \mathrm{N}$ are used. For ALOMAR, we use a longitude bin of $0^{\circ}-30^{\circ} \mathrm{E}$ and a latitude bin of $63^{\circ}-75^{\circ} \mathrm{N}$, i.e., the same latitudinal and longitudinal extent as in Kühlungsborn. These SABER time series have a time step of 1 day but we use averages over 5 days in this study, covering the time period 201218 , as for the lidar data.

\section{c. Gravity wave potential energy densities from reanalysis data}

The MERRA-2 and ERA5 datasets were interpolated in time and altitude to provide lidar like altitude profiles that were then analyzed in the same manner as the lidar data. The vertical profiles were interpolated to a fixed altitude spacing of $1 \mathrm{~km}$. We use reanalysis temperatures at ALOMAR and Kühlungsborn. The procedure of calculating GWPED is identical to the lidar data analysis described in section 1 and 

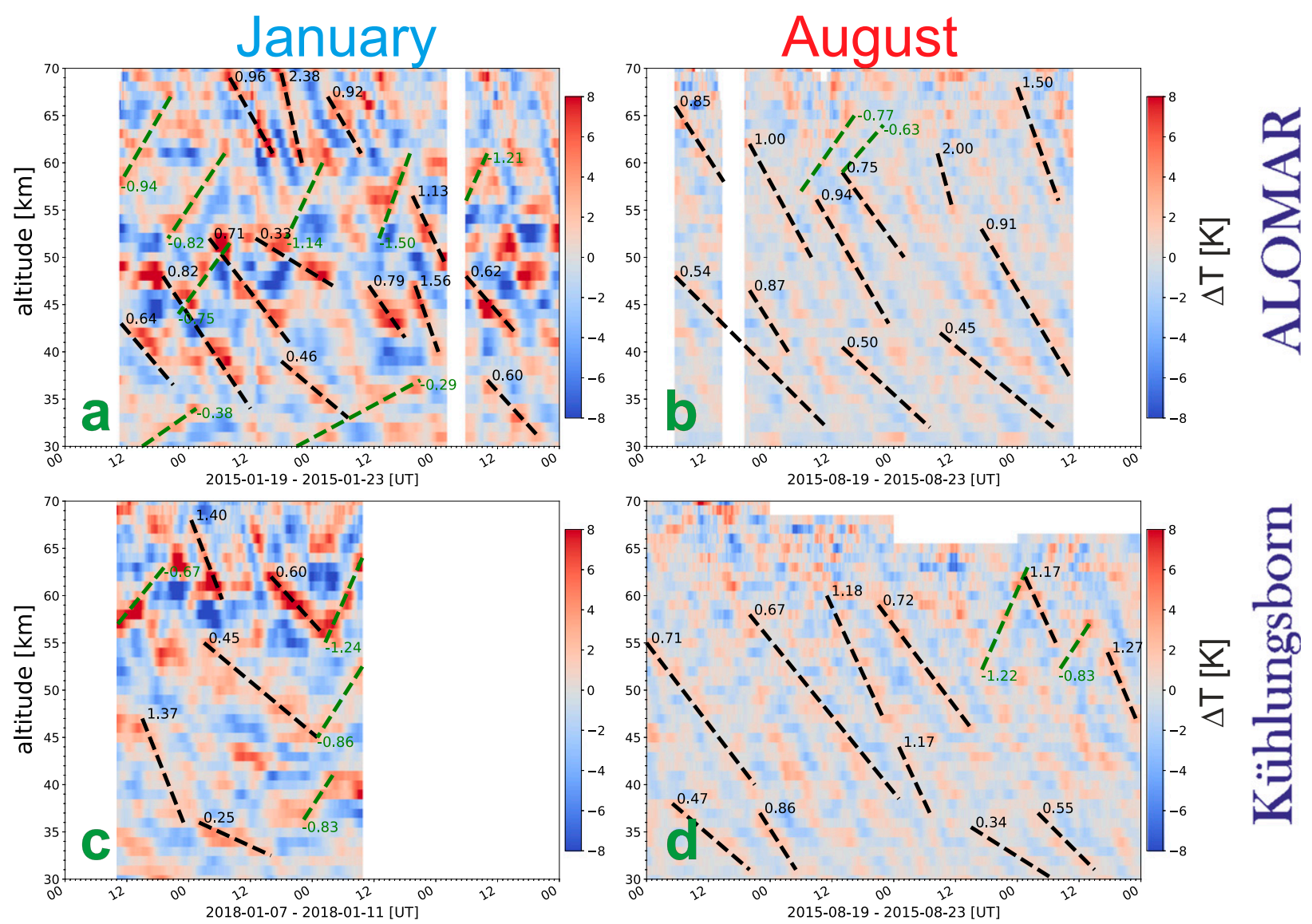

FIG. 3. Time-height cross sections of vertically filtered temperature fluctuations $\left(\lambda_{z}<15 \mathrm{~km}\right)$ in (left) January and (right) August at (top) ALOMAR and (bottom) Kühlungsborn for the same dates as in Fig. 1. Dashed lines mark phase lines where the numbers give the phase progression in $\mathrm{km} \mathrm{h}^{-1}$.

section 2. In particular, the reanalysis data are split into segments of $24 \mathrm{~h}$ before applying the analysis technique. An example of temperature fluctuations obtained from both datasets is shown in appendix $\mathrm{D}$ of this paper.

\section{Results}

\section{a. Lidar observations}

Figure 4 shows individual $E_{\mathrm{pV}}$ profiles obtained from vertically filtered data. For this plot 93 (41) winter and 119 (291) summer profiles obtained at ALOMAR (Kühlungsborn) are being used. The profiles are rather variable with altitude, season, and location. Day to day variability is more pronounced in winter than in summer. It turns out that individual values at a given altitude nearly follow a lognormal distribution. We have therefore calculated the standard deviation $(\sigma)$ of the logarithmic values of $E_{\mathrm{pV}}$ for all heights. In the altitude range $30-60 \mathrm{~km}$ the standard deviation at ALOMAR is in the range $0.5-0.6 \log \left(\mathrm{J} \mathrm{m}^{-3}\right)$ for summer and $0.7-0.85 \log \left(\mathrm{J} \mathrm{m}^{-3}\right)$ for winter. At Kühlungsborn these values are slightly lower, namely, $0.45-0.55 \log \left(\mathrm{J} \mathrm{m}^{-3}\right)$ in summer and $0.65-0.8 \log \left(\mathrm{J} \mathrm{m}^{-3}\right)$ in winter. At heights below $\sim 60 \mathrm{~km}$ the standard deviation does not show any significant height dependence. Above $60 \mathrm{~km} \sigma$ increases (decreases) slightly with altitude for summer (winter).

The decrease of $E_{\mathrm{pV}}$ shown in Fig. 4 is nicely described by an exponential function up to $\sim 55 \mathrm{~km}$. We have analyzed this decrease more quantitatively by fitting a function according to

$$
E_{\mathrm{pV}}(z)=E_{\mathrm{pV}}\left(z_{0}\right) \exp \left(-\frac{z-z_{0}}{H_{\mathrm{pV}}}\right) .
$$

We restrict the fit to the altitude range $30-55 \mathrm{~km}$ and derive the scale heights $H_{\mathrm{pV}}$ from the fit. The numbers for $H_{\mathrm{pV}}$ are provided in the Fig. 4. Generally speaking, $E_{\mathrm{pV}}$ decreases less rapidly with altitude in winter than in summer (scale heights are larger in winter). Above approximately $55 \mathrm{~km}$ the decrease of $E_{\mathrm{pV}}$ with altitude changes compared to below, i.e., the decrease is stronger in winter (but only at ALOMAR) and is weaker (or nearly constant) in summer at both locations. Results of scale heights $H_{\mathrm{pV}}$ obtained for appropriate height ranges are demonstrated and discussed in section 6 .

We also derived monthly mean values averaged in height bins of $5 \mathrm{~km}$, namely, 35-40, 45-50, and 55-60 km (see also Tables $\mathrm{C} 1$ and $\mathrm{C} 2$ in appendix $\mathrm{C}$ ). The results are shown in Fig. 5. In most cases there is a pronounced annual cycle at both 


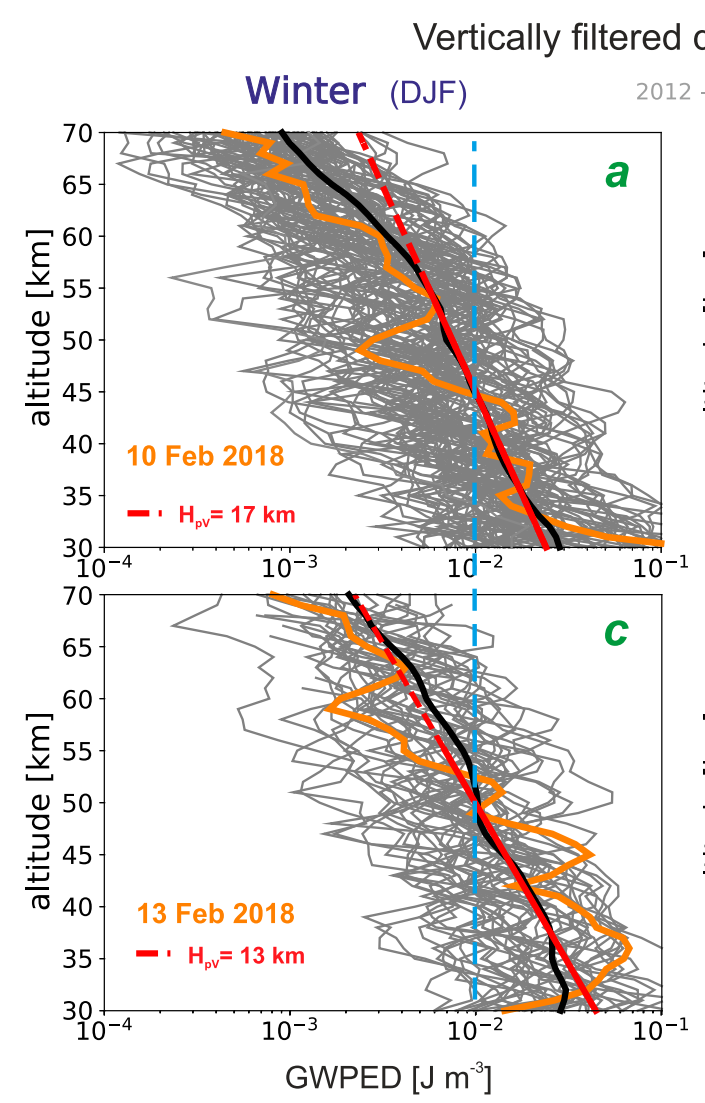

Summer (JJA)

FIG. 4. Vertically filtered $E_{\mathrm{pV}}$ profiles observed by lidar in (left) winter and (right) summer at (top) ALOMAR and (bottom) Kühlungsborn. Individual profiles are shown in gray. Thick black lines show mean values. Blue dashed lines mark a constant $E_{\mathrm{pV}}$ of $10^{-2} \mathrm{~J} \mathrm{~m}^{-3}$. Red lines mark linear fits of $\log \left[E_{\mathrm{pV}}(z)\right]$ where the slopes are given by the equivalent scale heights $H_{\mathrm{pv}}$ [see Eq. (3)]. For fitting we used the altitude range $30-55 \mathrm{~km}$. Orange profiles highlight some specific profiles, namely, observations (a) on 10 Feb 2018 at ALOMAR and (c) on 13 Feb 2018 at Kühlungsborn. For conservative propagation $E_{\mathrm{pV}}$ would be constant with height, marked here for an arbitrary value of $10^{-2} \mathrm{~J} \mathrm{~m}^{-3}$ (blue dashed line).

locations with maximum in winter and minimum in summer. This result is similar to previous studies of GW activity at other latitudes (e.g., Hirota 1984; Wilson et al. 1991; Whiteway and Carswell 1995; Eckermann 1995b; Rauthe et al. 2008; KB17; Hoffmann et al. 2017; Chu et al. 2018; Llamedo et al. 2019). We note that the situation can be more complex. For example, the seasonal variation is very pronounced for small wavelengths (vertically filtered data) at both locations and in all altitude ranges (Figs. 5b,e), whereas it is much smaller or even absent for small periods (temporally filtered data). Occasionally there are also semiannual variations present in Fig. 5, namely, in the unfiltered data in the altitude range $55-60 \mathrm{~km}$ at Kühlungsborn (Fig. 5d) and in the lower altitude ranges (35-40 and $45-50 \mathrm{~km}$ ) at ALOMAR (Fig. 5a) where minima occur in April/September and secondary maxima in summer. The largest GWPED values are observed in January independent of height range, location, or filtering method. As expected, unfiltered data contain larger GWPED values compared to filtered data (vertically or temporally) since they include a larger portion of the GW spectrum as well as some contributions from tides (see Fig. 2). The results will be discussed in more detail in section $5 \mathrm{~b}$.
As can be seen in Fig. 5 nearly all cases reveal a decrease of energy with altitude, as has been shown in detail for the vertically filtered data in Fig. 4. The strongest decrease is observed for small wavelengths (vertically filtered data). To the contrary, GW with small periods (temporally filtered data) show comparatively little variation with altitude: the results for 45-50 and $55-60 \mathrm{~km}$ are basically identical.

In Fig. $5 \mathrm{~g}-\mathrm{i}$ the ratios of climatologies obtained at both locations are also shown. $E_{\mathrm{pV}}$ from filtered observations (temporally or vertically) are generally larger by a factor of 2 in Kühlungsborn compared to ALOMAR, which is true for all seasons. $E_{\mathrm{pV}}$ from unfiltered data (Fig. $5 \mathrm{~g}$ ) are similar in summer in Kühlungsborn and ALOMAR, whereas the difference is again a factor of 2 in winter. It is important to note that the Kühlungsborn/ALOMAR ratios of $E_{\mathrm{pV}}$ do not substantially depend on altitude.

We have studied GWPED in more detail by calculating ratios of mean GWPED for winter (DJF) relative to summer (JJA). The results are shown in Fig. 6 as a function of altitude for both stations and for all filtering methods. At both stations, ratios are largest for vertically filtered data (small wavelengths), namely, 

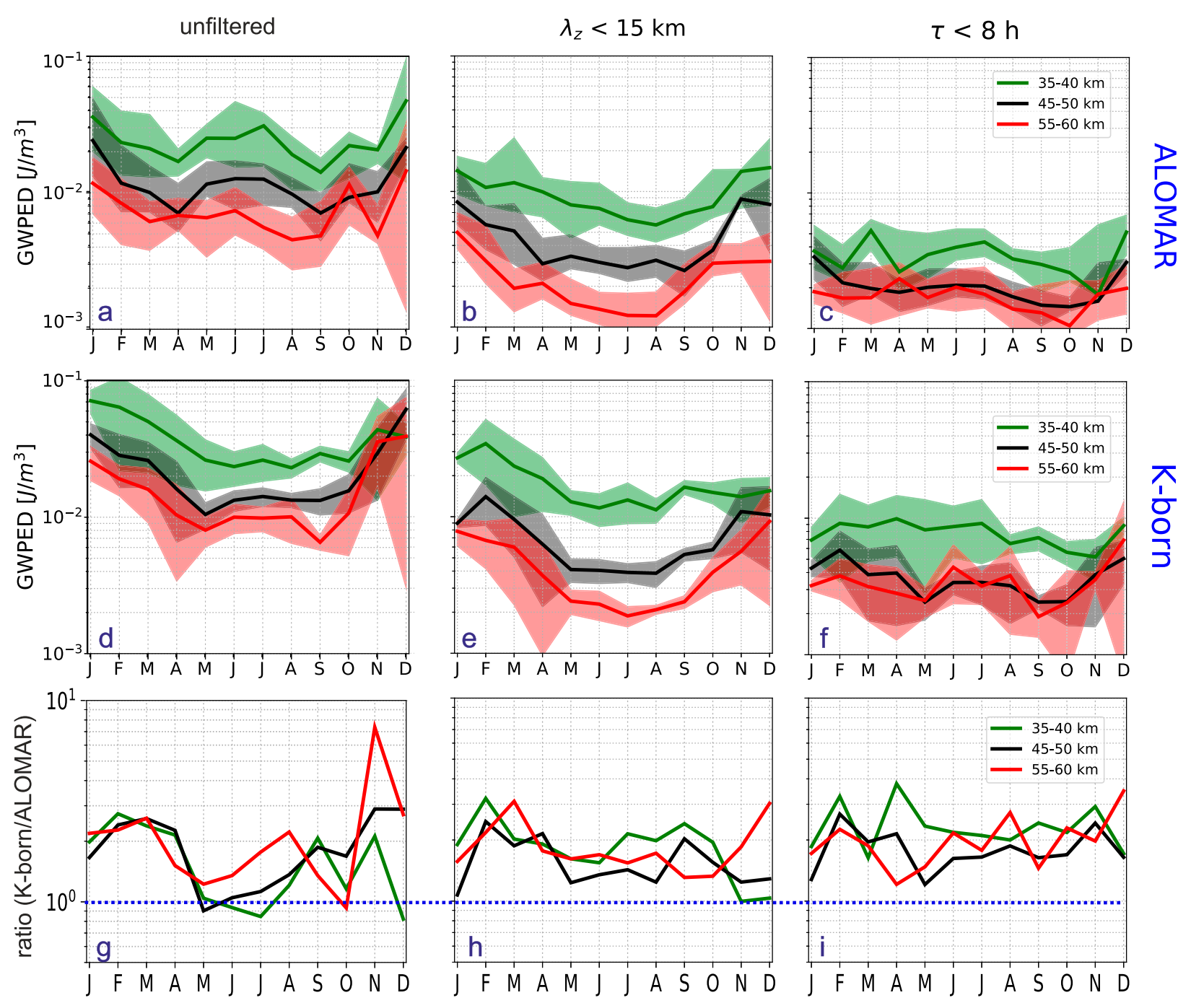

FIG. 5. Seasonal cycle of $E_{\mathrm{pV}}$ at (a)-(c) ALOMAR and (d)-(f) Kühlungsborn at selected altitude ranges: 35-40 km (green), 45-50 km (black), and 55-60 km (red). Each column represents three methods used to calculate $E_{\mathrm{pv}}$ : (left) unfiltered, (center) vertically filtered, and (right) temporally filtered. (a)-(f) Shaded regions describe the lognormal standard deviation. (g),(h),(i) The ratios of $E_{\mathrm{pV}}$ at Kühlungsborn relative to $E_{\mathrm{pV}}$ at ALOMAR.

$\sim 2-3$ in the lower stratosphere and lower mesosphere with a maximum of roughly 4 around the stratopause. Unfiltered or temporally filtered data show smaller winter/summer ratios, i.e., between 1 and $2-3$. Note that winter/summer ratios are close to 1 at the uppermost altitude, independent of location and filtering method. The altitude variation of winter/summer ratios for vertically filtered data can be understood by comparing the GWPED profiles shown in Fig. 4. For example, the decrease of $E_{\mathrm{pV}}$ with altitude is weaker in winter (larger-scale heights) compared to summer. Therefore, winter/summer ratios increase with altitude up to $\sim 55 \mathrm{~km}$. Above $\sim 55 \mathrm{~km} E_{\mathrm{pV}}$ in summer are almost constant with altitude at both stations, whereas winter values decrease further with height. Therefore, the winter/summer ratios drop above this altitude (see Fig. 6). For the other filtering techniques (vertically and temporally) the variation with altitude is rather similar, although less pronounced.
In Fig. 6 we also show winter/summer ratios for $E_{\mathrm{pm}}$, i.e., for GWPED per unit mass [see Eq. (1)]. Note that all quantities required to calculate $E_{\mathrm{pm}}$ are derived from our lidar observations, e.g., $T^{\prime}(z), T_{0}(z)$, and $N(z)$. As can be seen in Fig. 6 the winter/summer ratios for $E_{\mathrm{pm}}$ are significantly larger compared to $E_{\mathrm{pV}}$ both at ALOMAR and at Kühlungsborn. This is a consequence of the seasonal variation of temperatures and (for $\left.E_{\mathrm{pV}}\right)$ of mass densities, which vary with altitude and with location. For example, winter/summer ratios of $E_{\mathrm{pV}}$ at ALOMAR are smaller than of $E_{\mathrm{pm}}$ because mass densities in winter (at a given altitude) are smaller compared to summer.

Note that most climatologies published so far consider $E_{\mathrm{pm}}$ (and not $E_{\mathrm{pV}}$ ) or only temperature fluctuations. There have been theoretical attempts to circumvent this deficiency or to attribute observed differences to the background atmosphere (e.g., Alexander 1998; Eckermann 1995b). If possible, one 

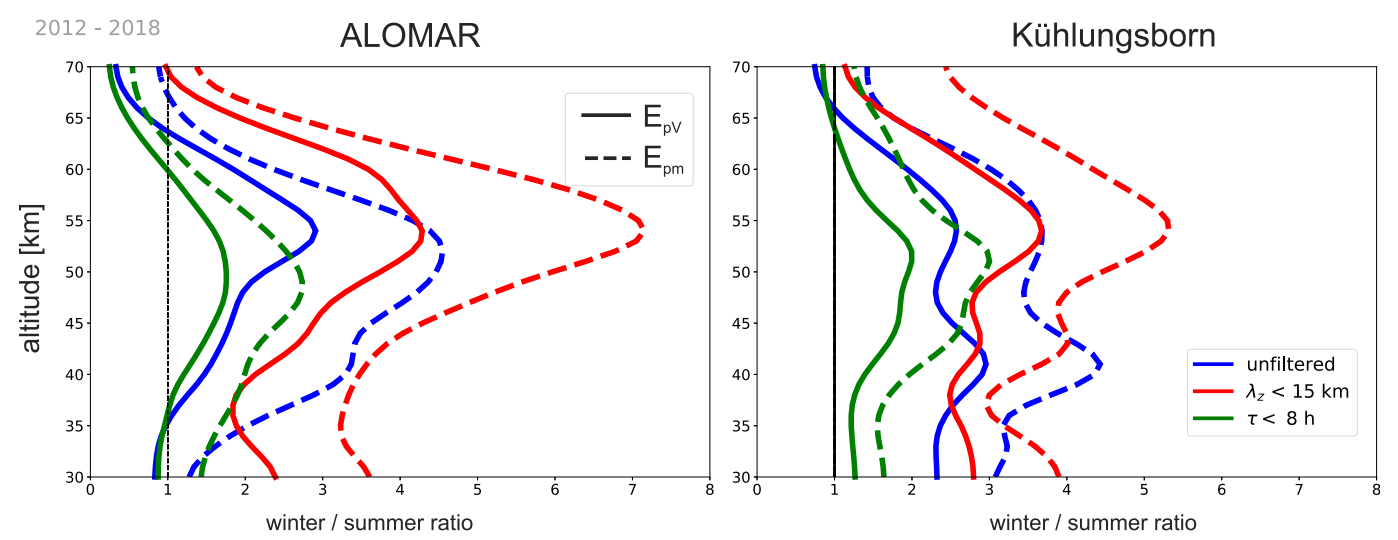

FIG. 6. Ratios of mean GWPED in winter (DJF) to summer (JJA) for different cases as observed by lidar. Solid lines are calculated from $E_{\mathrm{pV}}$ and dashed lines are calculated from $E_{\mathrm{pm}}$. Blue, red, and green colors are for unfiltered, vertically filtered, and temporally filtered data, respectively. (left) ALOMAR; (right) Kühlungsborn.

should determine GWPED per unit volume $\left(E_{\mathrm{pV}}\right)$ for comparison, because it accounts for different density, $\rho(z)$, buoyancy frequency, $N(z)$, and temperature profiles, $T(z)$, and it is a conserved quantity in case of undistorted propagation. Since $\rho(z), N(z)$, and $T(z)$ are substantially different in winter compared to summer, $E_{\mathrm{pV}}$ instead of $E_{\mathrm{pm}}$ should be used to interpret winter/summer ratios of GW activity at different locations in terms of atmospheric processes such as GW sources, filtering, and dissipation. Also variability of $N(z)$ and $T(z)$ reduces winter/summer ratios above ca. $60 \mathrm{~km}$ (e.g., Rauthe et al. 2006).

Could it be that our GWPED values in winter are biased because of the occurrence of sudden stratospheric warmings (SSW)? There are some indications that GW activity in the stratosphere/lower mesosphere is rather low because of SSW-related background wind conditions (Ern et al. 2016). Whether, or not, a climatology of GW at a certain station like ALOMAR or Kühlungsborn is affected by SSW depends on several factors. Apart from the fraction of measurements being made during SSW, the location of the station relative to the polar vortex, the strength of the SSW, as well as sources and propagation conditions of $\mathrm{GW}$ in the distorted wind field are important. In Fig. 4 individual profiles observed during an SSW in February 2018 are shown at ALOMAR (10 February 2018) and Kühlungsborn (13 February 2018). Obviously, the $E_{\mathrm{pV}}$ profiles during these days are not exceptionally small or large compared to other days. Furthermore, we note that the profiles with the smallest values in Fig. 4 were not detected during an SSW. In addition, only a small fraction of the observations in winter took place during an SSW. We conclude that it is rather unlikely that SSW lead to a significant bias of our GWPED climatology in winter. We repeat that a more careful analysis of SSW effects on GWPED is needed taking into account the complicated effects mentioned above. This is beyond the scope of this paper.

\section{b. Results from SABER}

Figure 7 gives an overview of the spatial and seasonal variation of $E_{\mathrm{pv}}$ at northern middle and high latitudes for winter and summer at $\sim 40 \mathrm{~km}$ altitude. Different from lidar, we selected January, February, and March for the winter season (Fig. 7a), and May, June, and July for the summer season (Fig. 7b). This selection is based on poor data coverage at high latitudes in other months which in turn is a consequence of the yaw cycle of the satellite. For a first overview, these data were averaged over $20^{\circ}$ in latitude. Figure 7 shows that $E_{\mathrm{pV}}$ in winter is approximately 3 times larger than in summer for the whole area. In winter $E_{\mathrm{pV}}$ at Kühlungsborn is nearly a factor of 2 larger than at ALOMAR. For summer this difference is smaller, but still, wave activity at middle latitudes is generally larger compared to high latitudes. As can be seen from Fig. 7a there is a substantial variation with longitude of $E_{\mathrm{pV}}$ in winter by nearly a factor of 2 , both at middle and high latitudes. Moreover, Kühlungsborn is located close to a zonal maximum, whereas ALOMAR is in a minimum. In contrast, in the Alaskan sector the differences between $\sim 55^{\circ}$ and $\sim 70^{\circ}$ are very small. The reason for this longitudinal variation of $E_{\mathrm{pV}}$ in winter is presumably related to the position of the polar vortex, which is usually slightly shifted to the European sector (e.g., Sato et al. 2009; Ern et al. 2016). A detailed analysis of longitudinal variations of $E_{\mathrm{pV}}$ is outside the scope of this paper.

For a more detailed comparison with lidars we select SABER data at the geographic locations of ALOMAR and Kühlungsborn and process the data similar to the lidar observations shown in Fig. 5. The results are shown in Fig. 8 and were derived as described in section $3 \mathrm{~b}$. This implies that the spectral range used to obtain the seasonal cycle from SABER is not exactly identical to one of those used for lidars. We therefore cannot expect an exact agreement.

Figure 8 shows $E_{\mathrm{pV}}$ averaged over $\pm 6^{\circ}$ in latitude in the period 2012-18. All available data have been used (solid lines). Since lidars operate only during favorable weather conditions, we extended the comparison by selecting only those days for SABER when lidars where in operation (dashed lines in Fig. 8). As can be seen, the difference is negligible in summer and still less than roughly $20 \%$ in winter. Winter months are more sensitive to data selection since the data coverage is worse than in summer and the variability is larger. 


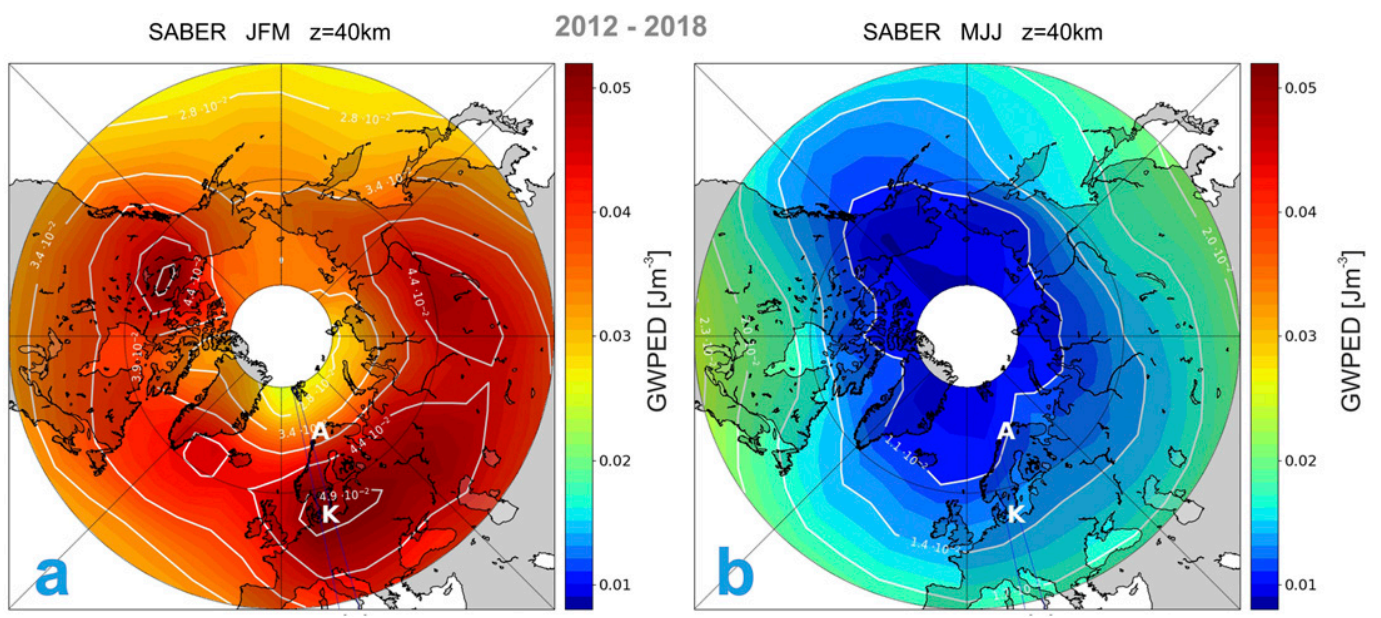

FIG. 7. SABER measurements of GWPED per unit volume at $40 \mathrm{~km}$ altitude for (left) winter months (JanuaryMarch) and (right) summer months (May-July) averaged over 7 years (2012-18). The locations of ALOMAR and Kühlungsborn are indicated by symbols " $\mathrm{A}$ " and "K," respectively.

Individual $E_{\mathrm{p} v}$ profiles derived from SABER during winter and summer are shown in Fig. 9. Note, that only profiles during dates of lidar observations are considered. In total there are 88 (49) profiles in winter (summer) at ALOMAR and 41 (291) profiles in Kühlungsborn. These profiles exhibit larger variability during winter than in summer, consistent with lidar results. Standard deviations of logarithmic values $(\sigma)$ are around $0.2 \log \left(\mathrm{J} \mathrm{m}^{-3}\right)$ in summer at both locations and $0.55 \log \left(\mathrm{J} \mathrm{m}^{-3}\right)$ in winter at ALOMAR and $0.45 \log \left(\mathrm{J} \mathrm{m}^{-3}\right)$ in Kühlungsborn. The variability in winter decreases above $\sim 60 \mathrm{~km}$. Generally speaking the variability of $E_{\mathrm{pV}}$ from SABER is smaller compared to lidar (Figs. 4 and 13). This is perhaps due to different averaging: whereas lidar data are only averaged in time, SABER observations are averaged in time and horizontal distance.

In Fig. 10 ratios of winter to summer values of mean $E_{\mathrm{pV}}$ at ALOMAR and Kühlungsborn as derived from SABER (limited to days during lidar operations, separately defined for each locations) are shown. Although there is substantial variation with altitude, the profiles of $E_{\mathrm{pV}}$ ratios are rather similar for ALOMAR and Kühlungsborn locations. The winter/summer ratio of $E_{\mathrm{pV}}$ averaged in the altitude range $30-61 \mathrm{~km}$ is equal to
$3.7 \pm 0.4$ at Kühlungsborn and $3.2 \pm 0.3$ at ALOMAR, i.e., they are identical within error bars. $E_{\mathrm{pm}}$ shows larger variability with height. The averaged ratio of $E_{\mathrm{pm}}$ is $6 \pm 0.8$ at Kühlungsborn and ALOMAR. The ratios shown in Fig. 10 are larger when comparing with lidar (Fig. 6), except for vertically filtered data in the altitude range around $55 \mathrm{~km}$, where ratios from lidar are maximal.

\section{c. Results from reanalysis data}

The seasonal variation of the vertically filtered $E_{\mathrm{pV}}$ at ALOMAR obtained from ERA5 and MERRA-2 in the height bins 35-40, 45-50, and 55-60 km are shown in Fig. 11. We have also applied the other filtering techniques (unfiltered and temporally filtered) and derived a complete set of seasonal $E_{\mathrm{pV}}$ variations both for ALOMAR and Kühlungsborn in the three altitude ranges used in this paper. The results are presented in appendix A. As can be seen in Fig. 11 there is basically no seasonal variation of $E_{\mathrm{pv}}$ present in ERA5, whereas MERRA-2 reveals a pronounced seasonal variation with maximum values in winter and minimum in summer. A semiannual variation is also present in the uppermost altitude bin $(55-60 \mathrm{~km})$ both in ERA5 and MERRA-2.
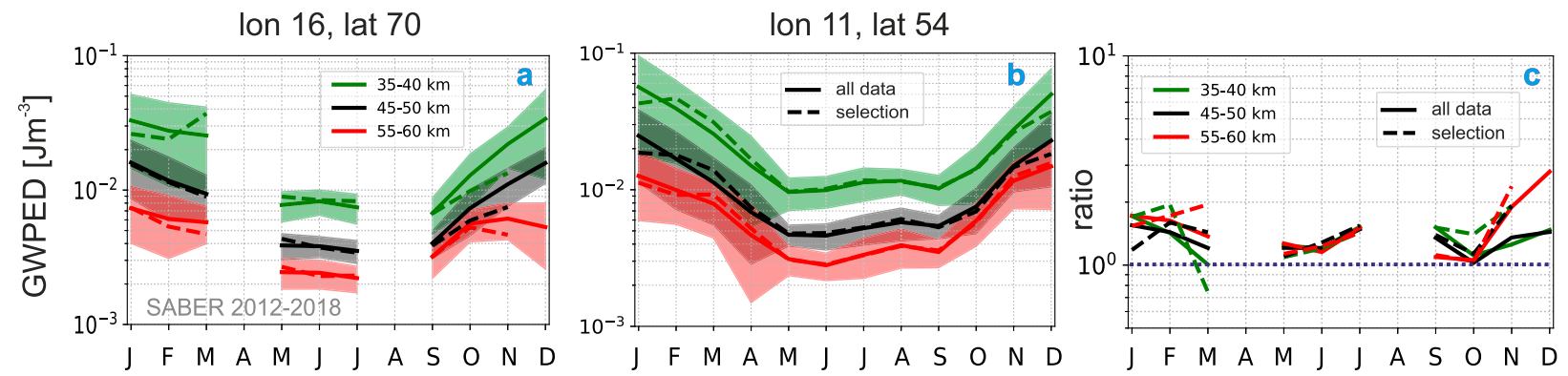

FIG. 8. Seasonal cycle of $E_{\mathrm{pV}}$ from SABER measurements averaged over 7 years (2012-18) at (left) $70^{\circ} \mathrm{N}, 16^{\circ} \mathrm{E}$ and (center) $54^{\circ} \mathrm{N}, 11^{\circ} \mathrm{E}$. (right) The ratio between the locations. The color index is as in Fig. 5. There are no observations at $70^{\circ} \mathrm{N}, 16^{\circ} \mathrm{E}$ in April and August during the whole $7 \mathrm{yr}$ period. Solid lines are for all available data; dashed lines are for simultaneous observations with lidar. 


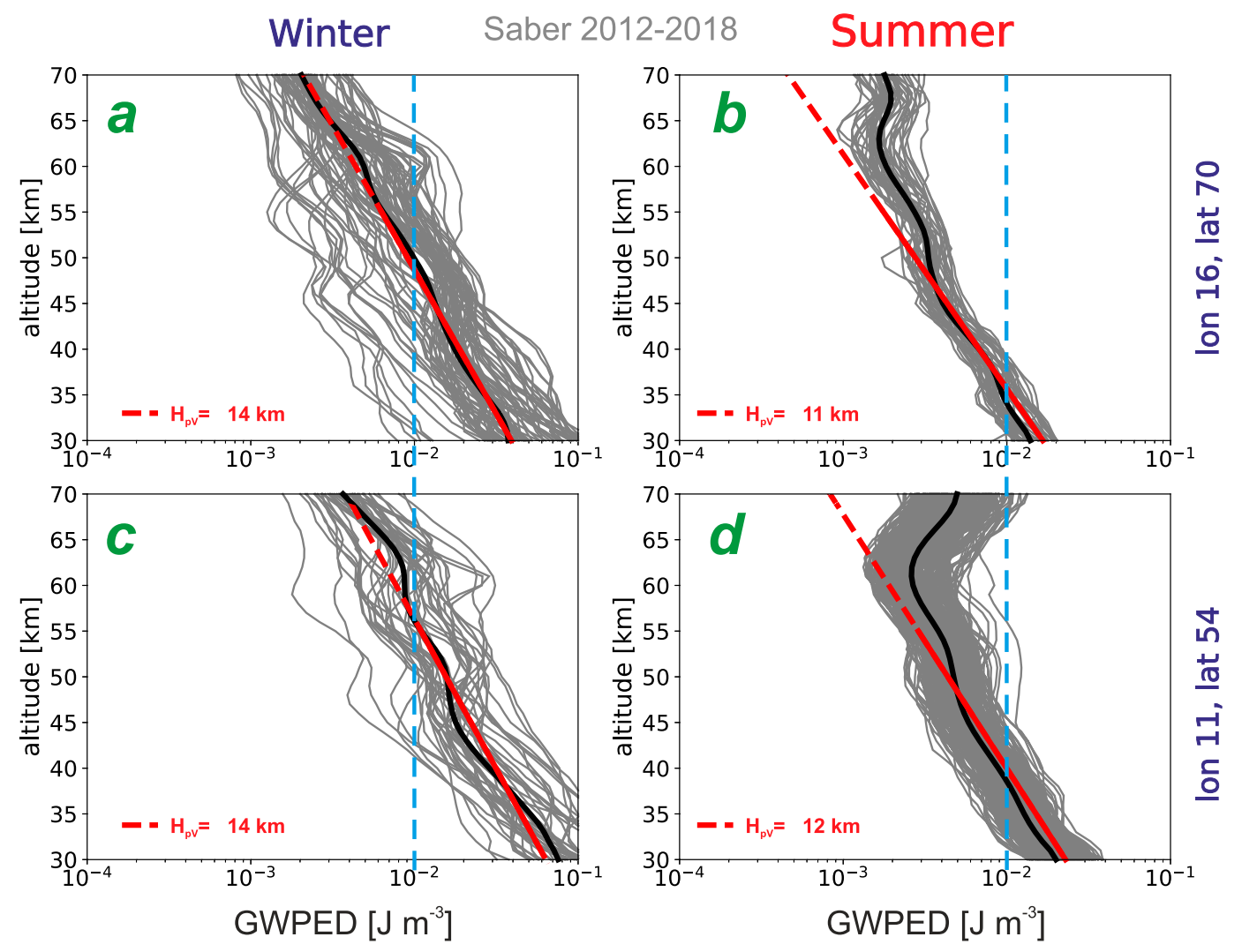

FIG. 9. As in Fig. 4, but from SABER observations.

As with SABER we used reanalysis data to examine the potential impact of the operational constraints of lidar (clearsky condition) on the final results. For this purpose we determined monthly mean values from ERA5 using all available profiles and compared the results with days when the lidar was in operation. The same procedure was repeated for MERRA-2. As can be seen in Fig. 11 (dashed lines) the differences are rather small. $E_{\mathrm{pV}}$ with preselection of days according to lidar operation are slightly larger, both for ERA5 and MERRA-2, but the differences are generally smaller than the natural variability. We have expanded this analysis by averaging over winter (DJF) and summer (JJA) months. The results are shown in Fig. 12 for vertically filtered data from ERA5 for summer and winter and for both locations. In summer the profiles are practically identical. In winter the restriction in ERA5 to lidar days leads to slightly higher GWPED, but the differences are usually smaller than typically $20 \%$. We conclude that the climatology derived from lidar observations can be considered representative regarding the seasonal variation at these locations. The results are not severely biased because lidar operation is restricted to clear weather conditions.

Regarding the comparison of the two stations, Fig. 11 shows that $E_{\mathrm{pV}}$ is generally larger by a factor of 1-2 in Kühlungsborn compared to ALOMAR (for vertically filtered data) in agreement with lidar results (see Fig. 5). Exceptions from this rule are mainly present during the winter months (both in ERA5 and MERRA-2) in particular in the lowest height bin (35-40 km).

\section{Comparison}

A summary of all $E_{\mathrm{pV}}$ profiles, including lidar, SABER, and reanalysis is presented in appendix $\mathrm{B}$. We note that more than 324 combinations of observations can be compared, namely, 2 stations, 3 instruments, 3 filter methods, 2 seasons, 3 altitude

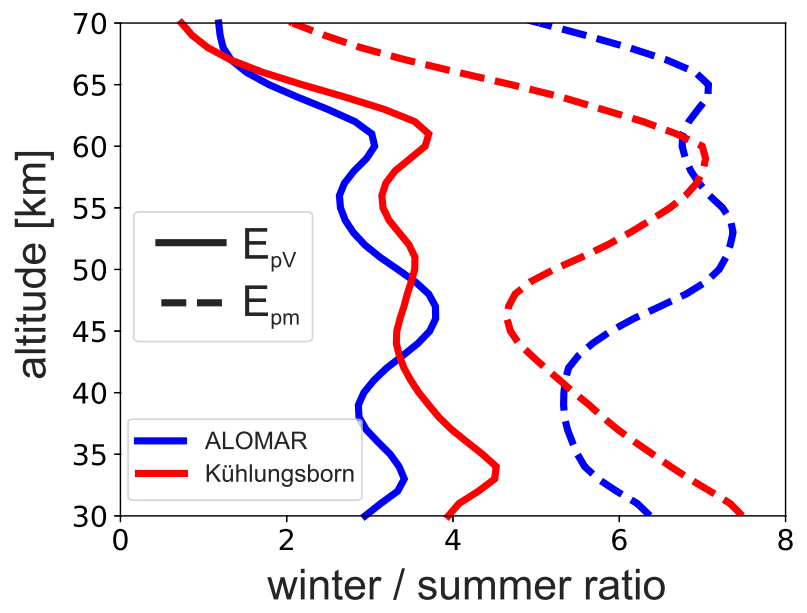

FIG. 10. Winter/summer ratios of mean GWPED obtained from SABER. Solid lines are for $E_{\mathrm{pV}}$, and dashed lines are for $E_{\mathrm{pm}}$. Blue is for ALOMAR, and red is for Kühlungsborn. 

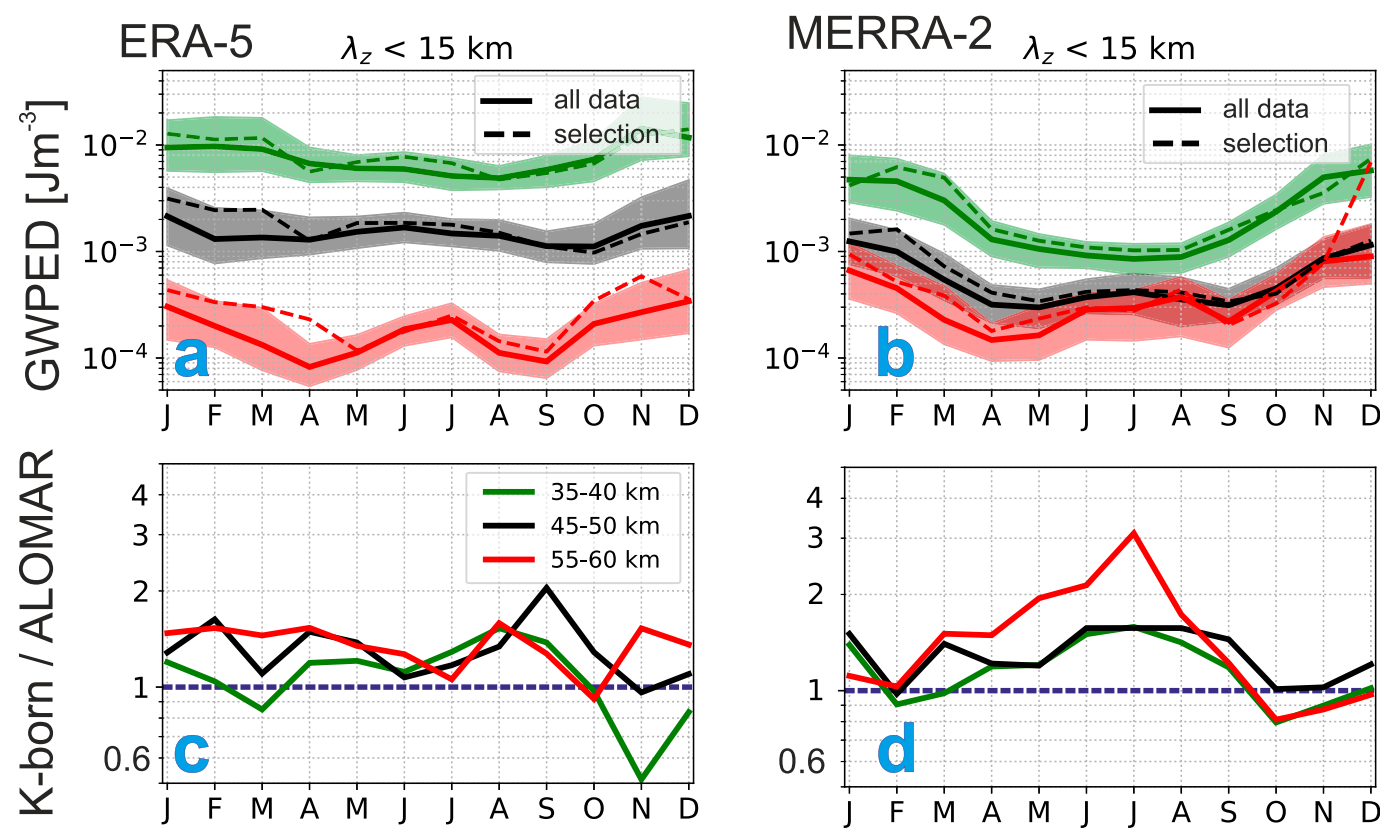

FIG. 11. (top) Seasonal cycle of GWPED $\left(E_{\mathrm{pV}}\right)$ obtained from (left) ERA5 and (right) MERRA-2 data for vertically filtered data at ALOMAR. Solid lines are for all available data; dashed lines are for days with lidar observations. Shaded regions show the standard deviations. (bottom) The ratios of $E_{\mathrm{pV}}$ at Kühlungsborn to $E_{\mathrm{pv}}$ at ALOMAR. The blue dashed lines represent a ratio of 1 . Colors indicate selected altitude ranges: $35-40 \mathrm{~km}$ (green), $45-50 \mathrm{~km}$ (black), and 55-60 km (red). Note the different scales on the $Y$ axis compare to Figs. 5 and 8.

ranges, and 3 parameters $\left(E_{\mathrm{pV}}, E_{\mathrm{pm}}, H_{\mathrm{pV}}\right)$. Here we focus on some selected aspects of a comparison between individual instruments, filtering techniques, seasons, locations, and height profiles.

When comparing SABER with lidar, several observational effects may cause differences that need to be taken into account. For example, the temporal and spatial sampling is different for both methods. Regarding SABER, the results for ALOMAR could be biased during months when the observation geometry changes between northward and southward because SABER does not cover high latitudes for the full month. This would affect the results in January, March, May, July, September, and November. Furthermore, results from SABER are derived by averaging over a horizontal range which is much larger compared to the field of view of the lidars. This can be important in regions where local gravity wave sources are to be expected, like the Scandinavian mountains close to ALOMAR. Regarding lidar, we can presumably rule out a bias due to restrictions to clear-sky conditions (see discussion in section $4 \mathrm{c}$ ). Taking these potential shortcomings into account, the results obtained by SABER and lidars are generally speaking in good agreement.

\section{a. Vertical profiles of $E_{p V}$ at Kühlungsborn and ALOMAR}

Lidar observations show larger $E_{\mathrm{pV}}$ in Kühlungsborn compared to ALOMAR, which is consistent with the differences between both stations derived from SABER. We note that this difference is somewhat smaller in SABER compared to lidar. This is presumably an effect of latitudinal averaging in SABER.
In Fig. 13 vertical profiles of $E_{\mathrm{pV}}$ from SABER are compared with lidar applying all three filter methods described in section 1 . Nearly all profiles show a decrease of $E_{\mathrm{pV}}$ with height, except for summer above $\sim 55 \mathrm{~km}$ where values are nearly constant or even increase with height. We will study this case in more detail in section 6 when comparing with background winds. As expected, both filtering methods $\left(\lambda_{z}<15 \mathrm{~km}\right.$ and $\tau<8 \mathrm{~h}$ ) significantly reduce $E_{\mathrm{pV}}$ at all altitudes and at both stations since filtering removes a substantial part of the gravity and tidal wave spectrum.

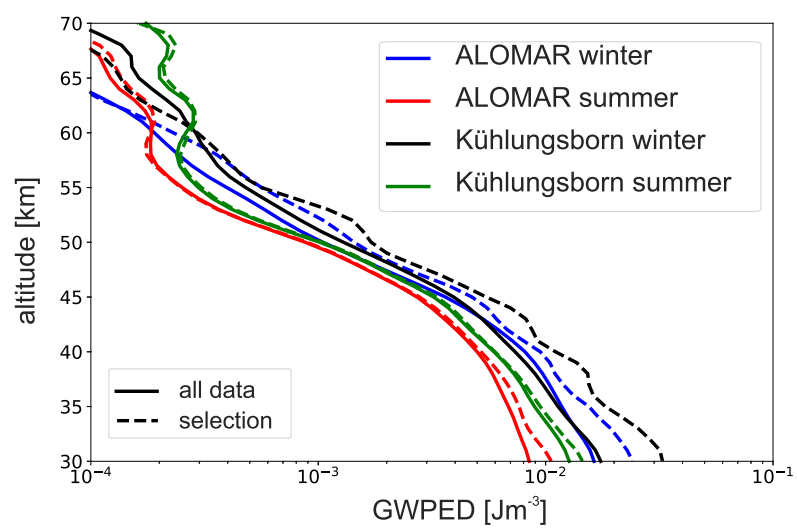

FIG. 12. Profiles of $E_{\mathrm{pV}}$ obtained from vertically filtered ERA5 data. Solid lines are for all data; dashed are for days with lidar observations only. 
Winter
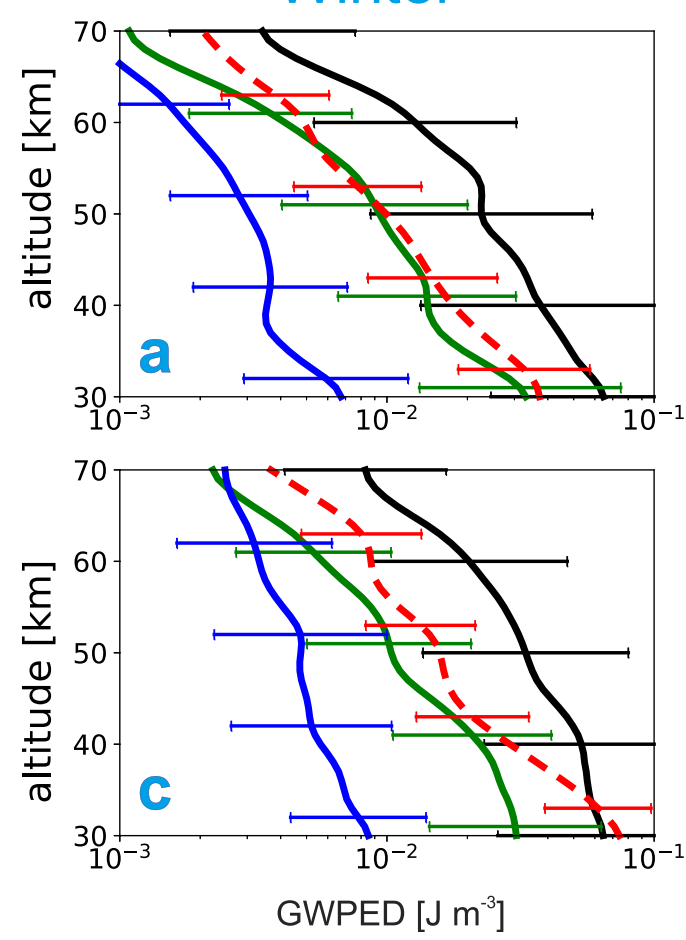

Summer
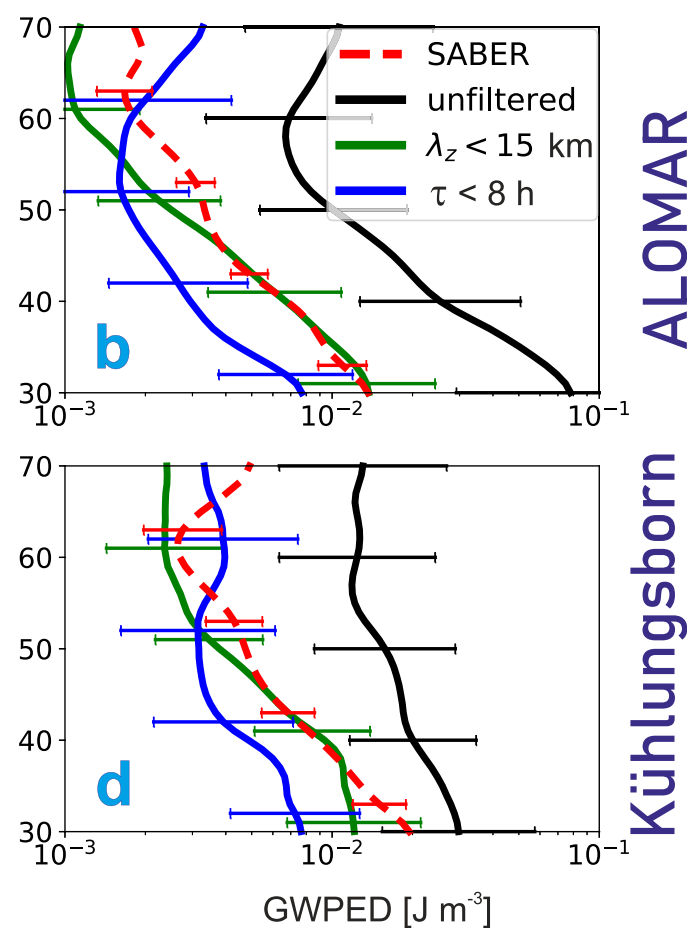

FIG. 13. Profiles of $E_{\mathrm{pV}}$ observed by lidar (solid lines) and SABER (dashed lines) for (left) winter and (right) summer at (top) ALOMAR and (bottom) Kühlungsborn. Black, green, and blue colors indicate different filtering methods. Standard deviations of logarithmic values $(\sigma)$ are shown as error bars.

In Fig. 14 altitude profiles of ratios of $E_{\mathrm{pV}}$ from SABER relative to lidar are shown. The values of $E_{\mathrm{pV}}$ from vertically filtered lidar data are rather close to SABER and are sometimes nearly identical, for example below $\sim 45 \mathrm{~km}$ in summer at both stations. We recall that the data processing applied for SABER removes all waves with large periods ( $>1-2$ days) and waves with zonal wavenumbers up to six which corresponds to horizontal wavelengths of roughly $\lambda_{x} \sim 3300 \mathrm{~km}$ for $60^{\circ} \mathrm{N}$. SABER data used here contain vertical wavelengths in the range 4 to $25 \mathrm{~km}$. In summary, SABER covers wavelengths in the range $200<\lambda_{x}<3300 \mathrm{~km}, 4<\lambda_{z}<25 \mathrm{~km}$, and lidars (vertically filtered) cover wavelengths $10 \mathrm{~km}<\lambda_{x}<$ several thousand kilometers, $\lambda_{z}<15 \mathrm{~km}$. The fact that $E_{\mathrm{pV}}$ from lidar (vertically filtered) and SABER are so close to each other implies that $E_{\mathrm{pV}}$ outside the common horizontal/vertical wavelength range are either nearly equal or negligible. We note that GW with $\lambda_{z}$ between 1 and $15 \mathrm{~km}$ and $\lambda_{x}$ of several hundred kilometers propagate very obliquely (phase propagation close to the horizon). As can also be seen in Fig. $14 E_{\mathrm{pV}}$ from SABER is generally larger compared to lidar if temporal filtering $(\tau<8 \mathrm{~h})$ is applied, and smaller if no filtering is applied.

A comparison of $E_{\mathrm{pV}}$ from reanalysis and lidar is shown in Fig. 15. We concentrate on vertically filtered lidar data $\left(\lambda_{z}<\right.$ $15 \mathrm{~km})$ since some systematic effects are most pronounced here. A complete set of comparisons is presented in appendix B. As can be seen from Fig. $15, E_{\mathrm{pV}}$ from ERA5 and MERRA-2 are generally smaller compared to lidar where the difference increases with altitude in winter and reaches up to two orders of magnitude around $70 \mathrm{~km}$. In summer the situation is more complicated. The values of $E_{\mathrm{pV}}$ from ERA5 agree roughly with lidar up to $\sim 50 \mathrm{~km}$, whereas MERRA-2 is smaller than lidar by approximately one order of magnitude in the same altitude range. Above $\sim 50 \mathrm{~km}$ (in summer) it is the other way around: the difference between lidar and reanalysis is larger for ERA5 and smaller for MERRA-2. The spatial resolution in MERRA-2 is worse compared to ERA5 (see section 2d). This presumably explains why $E_{\mathrm{pV}}$ from MERRA-2 are generally smaller compared to ERA5. On the other hand, damping in ERA5 increases more rapidly with altitude compared to MERRA-2 which explains why $E_{\mathrm{pV}}$ from ERA5 are smaller compared to MERRA-2 above $\sim 50 \mathrm{~km}$ (see, e.g., Copernicus Climate Change Service 2017; Global Modeling and Assimilation Office 2015).

\section{b. Seasonal variation of $E_{p V}$}

The values of $E_{\mathrm{pV}}$ from lidar (Fig. 5) and SABER (Fig. 8) both show a variation with season with minimum values in summer and maximum in winter at both locations and in all altitude ranges. The seasonal variation of $E_{\mathrm{pV}}$ from SABER at both locations is somewhat larger compared to lidar (see Figs. 6 and 10).

GWPED from SABER show a weak secondary maximum in summer in Kühlungsborn (a similar analysis cannot be made at 

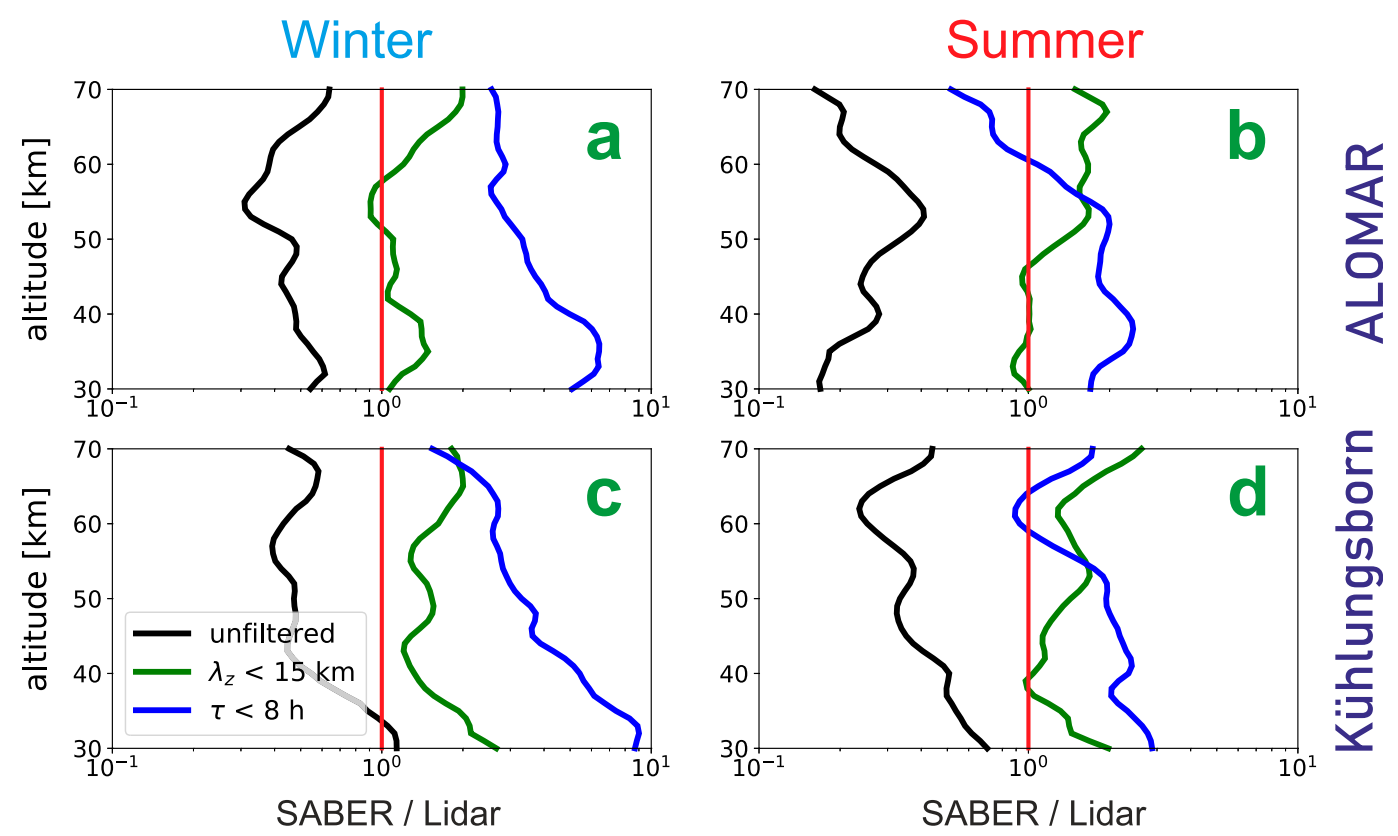

FIG. 14. Ratios of $E_{\mathrm{pV}}$ from SABER relative to lidar for (left) winter and (right) summer at (top) ALOMAR and (bottom) Kühlungsborn. Colors indicate different filtering methods (see key).

ALOMAR because the data coverage by SABER is too poor). The unfiltered lidar data shown in Figs. 5a and 5d confirm this increase in the summer months at both stations. This increased activity is absent in the filtered lidar data (both filters and all altitudes, Figs. 5b,c,e,f). Could it be that the summer increase is due to tidal fluctuations in the unfiltered data? Diurnal tides show comparatively small variation with season at middle and high latitudes and at the relevant altitudes (e.g., Gan et al. 2014). Forbes and $\mathrm{Wu}$ (2006) reported largest amplitude of $\sim 5 \mathrm{~K}$ for the westward-propagating semidiurnal tide with zonal wavenumber 2 (SW2) at $60 \mathrm{~km}$ and an amplitude of $6 \mathrm{~K}$ for stationary planetary waves (SPW1) in winter, and 1-2 K for both components in summer. There are no indications for a significant semiannual cycle or higher harmonics. The unfiltered data could include some contribution from these tides. However, according to Forbes and Wu (2006) and Pancheva and Mukhtarov (2011) this contribution should be largest in winter which contradicts our comparison between SABER and unfiltered lidar measurements because the difference between SABER and lidar is larger in summer compared to winter at both locations. Our results suggest that a more detailed understanding of GW and tidal spectra and their seasonal variation as a function of wavelengths and frequencies is required to better understand the winter-summer difference.
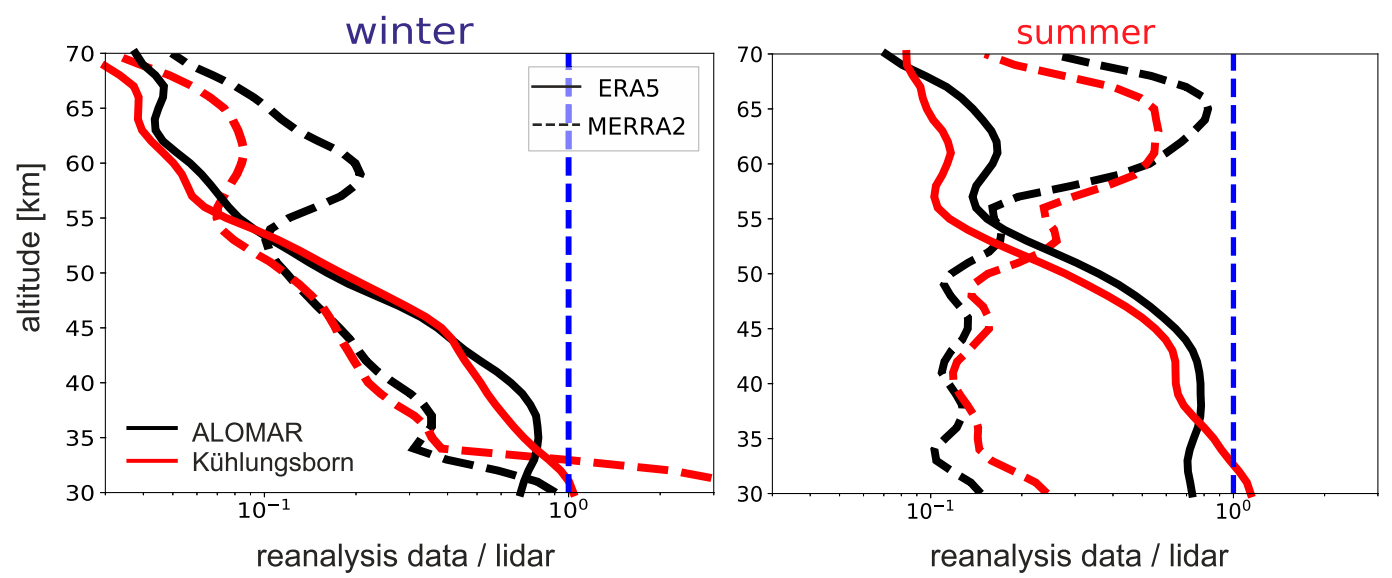

FIG. 15. Ratios of $E_{\mathrm{pV}}$ obtained from reanalysis data relative to lidar for vertically filtered data. (left) Winter months (DJF); (right) summer months (JJA). Solid lines are results from ERA5; dashed lines are from MERRA-2. Black is for ALOMAR; red is for Kühlungsborn. 
Regarding the comparison of $E_{\mathrm{pV}}$ from reanalysis (ERA5 and MERRA-2) with lidar and SABER we have seen that MERRA-2 qualitatively reproduces the seasonal variation measured by lidars, namely, larger values in winter compared to summer for unfiltered and vertically filtered data, and basically no variation for temporally filtered $E_{\mathrm{pV}}$. There is basically no seasonal variation for the vertically and temporally filtered data in ERA5.

\section{c. Variation of $E_{p V}$ with altitude}

In this section we present more details on the exponential decrease of $E_{\mathrm{pV}}$ noted in Figs. 4 and 9 for vertically filtered data from lidar and also from $\mathrm{SABER}$. We repeat that $E_{\mathrm{pV}}$ would be constant with altitude for undisturbed wave propagation with constant background wind. A decrease of $E_{\mathrm{pV}}$ with altitude implies that energy is removed from the GW field. Processes other than dissipation could contribute to the energy removal, for example, wave reflection or refraction or a shift of wavelengths or periods to values outside our filtering window. We characterize the altitude decrease of $E_{\mathrm{pV}}$ more quantitatively by fitting an exponential function according to Eq. (3) and derive the scale height $H_{\mathrm{pV}}$ from the fit. As can be seen in Fig. 13 a simple exponential decrease is well defined in certain height regions but is not appropriate in others. We therefore constrained the fitting procedure to certain altitude regions (see Table 3).

In the winter-summer comparison we concentrate on altitudes below $\sim 60 \mathrm{~km}$ since in summer $E_{\mathrm{pV}}$ is increasing (not decreasing) above this height. Scale heights $H_{\mathrm{pV}}$ deduced from lidar are generally larger in winter compared to summer. This is true for all filtering techniques and both stations, except for unfiltered data in Kühlungsborn. For example, regarding temporally filtered data, we derive $H_{\mathrm{pV}}=31.1 \mathrm{~km}$ and $H_{\mathrm{pV}}=$ $34.1 \mathrm{~km}$ in winter at ALOMAR and Kühlungsborn, respectively, whereas $H_{\mathrm{pV}}=17.4$ and $17.1 \mathrm{~km}$ in summer at these stations. In other words, the loss of gravity wave potential energy density with altitude is generally stronger in summer compared to winter. This observational result will be discussed in more detail in section 6 in connection with the background wind profiles.

We have checked if the shape of the density profiles taken from MSISE can affect the shape of the $E_{\mathrm{pV}}$ profiles. For this purpose we repeated the analysis with the density profiles measured by the lidar. The differences are less than $10 \%$ in most of the altitudes and do not influence our results.

For SABER, the winter-summer comparison is more complex but the difference is generally smaller compared to lidar. For example, at ALOMAR below $60 \mathrm{~km}$, the scale heights are nearly identical in winter and summer. In Kühlungsborn the difference varies with altitude. Regarding the scale heights from SABER compared to lidar, the situation is rather complex. The values of $H_{\mathrm{pV}}$ from SABER can be larger or smaller, depending on the station and the filtering method used for lidar. There is one exception, namely, winter in Kühlungsborn, where $H_{\mathrm{pV}}$ from SABER is smaller compared to lidar for all filtering methods. In this case GWPED decreases more rapidly with altitude for
TABLE 3. Obtained scale height $H_{\mathrm{pV}}$ from lidar and SABER observations for different altitude ranges.

\begin{tabular}{|c|c|c|c|c|}
\hline Station & Season & Method & $\begin{array}{c}\text { Altitude } \\
\text { range }(\mathrm{km})\end{array}$ & $H_{\mathrm{pV}}(\mathrm{km})$ \\
\hline \multirow[t]{17}{*}{ ALOMAR } & \multirow[t]{8}{*}{ Winter } & \multirow[t]{2}{*}{ Unfiltered } & $30-60$ & 20 \\
\hline & & & $60-70$ & 6.5 \\
\hline & & \multirow[t]{2}{*}{$\lambda_{\mathrm{z}}<15 \mathrm{~km}$} & $32-52$ & 19.8 \\
\hline & & & $52-70$ & 7.7 \\
\hline & & \multirow[t]{2}{*}{$\tau<8 \mathrm{~h}$} & $31-59$ & 31 \\
\hline & & & $61-70$ & 11.3 \\
\hline & & \multirow[t]{2}{*}{ SABER } & $32-60$ & 14.4 \\
\hline & & & $60-70$ & 11 \\
\hline & \multirow[t]{9}{*}{ Summer } & \multirow[t]{2}{*}{ Unfiltered } & $30-54$ & 9.6 \\
\hline & & & $59-70$ & -21 \\
\hline & & \multirow[t]{2}{*}{$\lambda_{\mathrm{z}}<15 \mathrm{~km}$} & $31-60$ & 11 \\
\hline & & & $60-70$ & -253 \\
\hline & & \multirow[t]{3}{*}{$\tau<8 \mathrm{~h}$} & $30-35$ & 7.3 \\
\hline & & & $35-50$ & 17.4 \\
\hline & & & $59-70$ & -14.6 \\
\hline & & \multirow[t]{2}{*}{ SABER } & $30-62$ & 15 \\
\hline & & & $62-70$ & -57 \\
\hline \multirow[t]{17}{*}{ Kühlungsborn } & \multirow[t]{8}{*}{ Winter } & \multirow[t]{2}{*}{ Unfiltered } & $31-60$ & 26 \\
\hline & & & $60-70$ & 9.4 \\
\hline & & \multirow[t]{2}{*}{$\lambda_{\mathrm{z}}<15 \mathrm{~km}$} & $30-54$ & 16 \\
\hline & & & $54-70$ & 10 \\
\hline & & $\tau<8 \mathrm{~h}$ & $30-70$ & 34 \\
\hline & & \multirow[t]{3}{*}{ SABER } & $31-45$ & 10 \\
\hline & & & $45-60$ & 18.5 \\
\hline & & & $60-70$ & 11 \\
\hline & \multirow[t]{9}{*}{ Summer } & \multirow[t]{2}{*}{ Unfiltered } & $30-57$ & 26 \\
\hline & & & $57-70$ & -147 \\
\hline & & \multirow[t]{3}{*}{$\lambda_{z}<15 \mathrm{~km}$} & $30-39$ & 190 \\
\hline & & & $39-52$ & 11 \\
\hline & & & $60-70$ & 401 \\
\hline & & \multirow[t]{2}{*}{$\tau<8 \mathrm{~h}$} & $30-51$ & 17 \\
\hline & & & $61-70$ & 217 \\
\hline & & \multirow[t]{2}{*}{ SABER } & $30-61$ & 16 \\
\hline & & & $61-70$ & -12 \\
\hline
\end{tabular}

SABER compared to lidar data regardless of filtering method. This indicates that different parts of the GW spectrum dissipate at different heights. We have also calculated $H_{\mathrm{pV}}$ from ERA5 and MERRA-2. As expected, the energy-scale heights are much smaller than in observations, as exemplarily indicated in the GWPED ratio in Fig. 15. More details can be found in appendix B. In other words, $E_{\mathrm{pV}}$ in ERA5 and MERRA-2 decreases significantly stronger with altitude compared to observations. We note that this decrease is to a large extent determined by technical specifications in the models, e.g., by damping coefficients.

\section{Discussion}

\section{a. General remarks}

In this section we discuss some of the results presented above in relationship to background winds. The concept that GW cannot pass a height region where the horizontal phase 

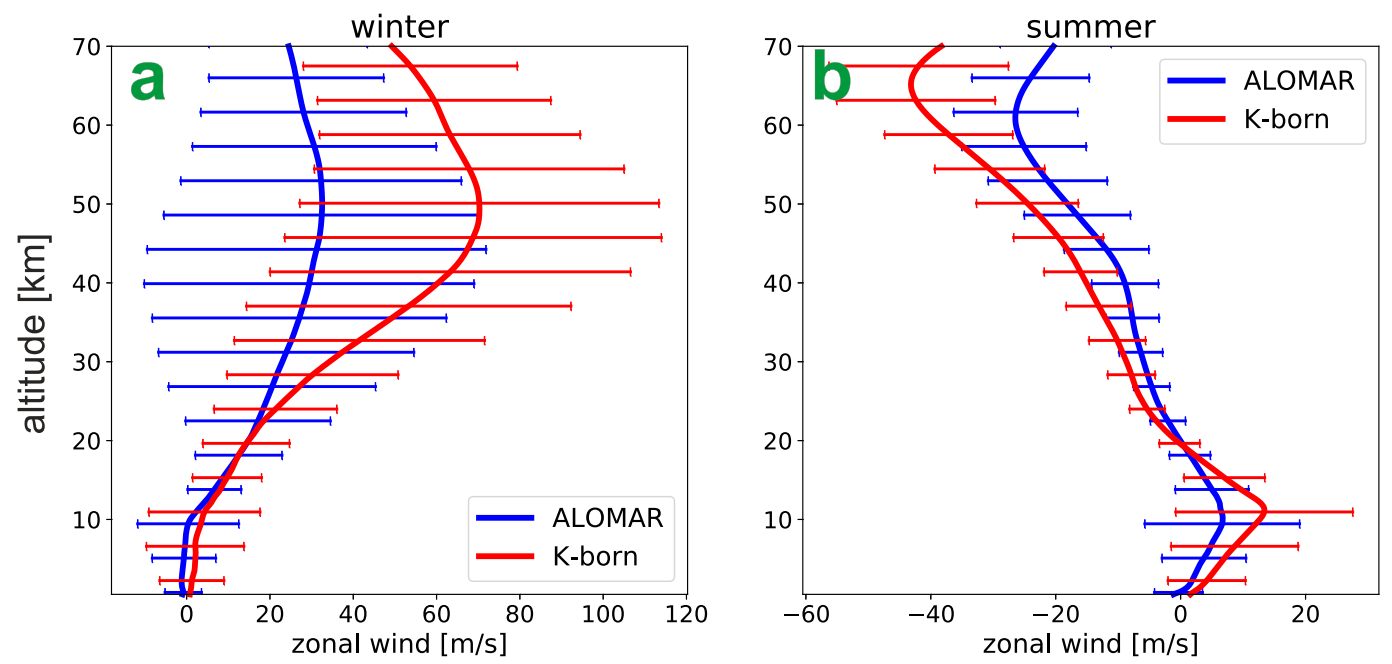

FIG. 16. Mean zonal winds obtained from ECMWF for days when the lidars were operating. (left) Winter season; (right) summer season. Blue is for ALOMAR; red is for Kühlungsborn. Error bars show standard deviations.

speed of GW equals the background wind velocity is a standard mechanism used to explain the winter-summer difference of GW forcing (e.g., Lindzen 1981; Whiteway and Duck 1999; Espy et al. 2004; Jiang et al. 2013). Furthermore, background winds cause a Doppler shift of wave parameters, e.g., of vertical wavelengths and wave periods (e.g., Fritts 1984; Eckermann 1995a; Alexander 1998):

$$
\begin{aligned}
\frac{1}{k_{z}^{2}} & =\left(\frac{\lambda_{z}}{2 \pi}\right)^{2}=\left(\frac{v_{\varphi, x}-\bar{u}}{N}\right)^{2}=\left(\frac{\hat{v}_{\varphi, x}}{N}\right)^{2}, \\
\tau_{\text {ground }} & =\tau_{\text {intrinsic }} \times\left(\frac{\hat{v}_{\varphi, x}}{\bar{u}+\hat{v}_{\varphi, x}}\right),
\end{aligned}
$$

where $\hat{\boldsymbol{v}}_{\varphi, x}$ and $\boldsymbol{v}_{\varphi, x}$ are the intrinsic and ground-based horizontal phase speeds of the $\mathrm{GW}, k_{z}$ and $\lambda_{\mathrm{z}}$ are vertical wavenumber and wavelength, respectively, $N$ is the Brunt-Väisälä frequency, $\bar{u}$ is the mean zonal wind, and $\tau_{\text {ground }}$ and $\tau_{\text {intrinsic }}$ are the periods observed at the ground and in a system moving with the background wind, respectively.

Generally speaking, GW detected by lidars or SABER are impacted by background winds, for example, by dissipation or by Doppler shifting. We therefore use winds from ECMWF for days when the lidars were operating and calculate mean profiles for both stations and for summer and winter (Fig. 16). A difference between both stations is rather prominent in winter above $\sim 30 \mathrm{~km}$ : zonal winds are stronger in Kühlungsborn compared to ALOMAR. This is presumably related to the geographic position of the polar night jet. The position of this jet is highly variable and is often shifted southward in the European sector, i.e., toward Kühlungsborn. Comparison of stratospheric zonal winds in Kühlungsborn and ALOMAR suggest that the polar night jet was on average located closer to Kühlungsborn than to ALOMAR, considering days of lidar observations only. We note that the wind situation can be more complicated, in particular during SSW. However, we have seen already in section 4a that SSW most likely do not cause a significant bias in our GWPED climatology.

\section{b. ALOMAR versus Kühlungsborn: Filtering?}

Our lidar observations show that GWPED at Kühlungsborn is larger compared to ALOMAR, especially during winter (Fig. 5). This result is confirmed by SABER (see Fig. 8), but not by MERRA-2 and ERA5 (Fig. 11). Can this difference be explained by filtering or Doppler shifting? Gravity waves cannot propagate further upward if they encounter a region where $v_{\varphi, x}=\bar{u}\left[\lambda_{z}=0 \mathrm{~km}\right.$, see Eq. (4)]. We would therefore expect that in winter filtering by zonal winds is stronger in Kühlungsborn than at ALOMAR because the range of winds encountered by GW on their way from the troposphere to the middle stratosphere is larger in Kühlungsborn (see Fig. 16). In this simple scenario one would therefore expect smaller GWPED in Kühlungsborn compared to ALOMAR, in particular at altitudes above the wind maximum at $\sim 40 \mathrm{~km}$. Our observations show the opposite, namely, larger GWPED in Kühlungsborn compared to ALOMAR, also at higher altitudes (see Fig. 5).

If Doppler shifting of GW is sufficiently strong, gravity waves could be shifted to wavelengths or periods which are outside the spectral region covered by vertical or temporal filtering, respectively. Of course, GW can also be shifted into the filtering windows. If, or not, this effect is relevant in our case depends on the source spectrum, the phase speeds of the waves, and the magnitude of the winds. For example, the vertical wavelength of a GW with $v_{\varphi, x}=0 \mathrm{~m} \mathrm{~s}^{-1}$ increases by $15 \mathrm{~km}$ if the background winds increases by $48 \mathrm{~m} \mathrm{~s}^{-1}$. Another example: the period of a GW with a phase speed of $v_{\varphi, x}=-7 \mathrm{~m} \mathrm{~s}^{-1}$ decreases by a factor of 4.7 in a background wind of $\bar{u}=40 \mathrm{~m} \mathrm{~s}^{-1}$ (maximum $\bar{u}$ at ALOMAR). The period of the same wave decreases by a factor of 9.7 if $\bar{u}=75 \mathrm{~m} \mathrm{~s}^{-1}$ (maximum $\bar{u}$ at Kühlungsborn). These examples show that Doppler shifting indeed needs to be considered for winds in the winter mesosphere at both stations. 
It is tempting to explain larger GWPED in Kühlungsborn compared to ALOMAR for temporally filtered data (lidar) by Doppler shifting since a larger part of GW with large periods (which are expected to have large GWPED) is shifted into the filtering window if background winds are larger (see numbers from above). However, the Kühlungsborn-ALOMAR difference is also present for vertically filtered data (covering all periods), and the difference is also present where the wind difference is much smaller, namely, at altitudes above $\sim 60 \mathrm{~km}$ (see Fig. 5). Regarding Doppler shifting of $\lambda_{z}$, it is again unlikely that this can explain the Kühlungsborn-ALOMAR difference in winter since Doppler shifting increases with increasing background velocities. Since maximum zonal winds are larger in Kühlungsborn compared to ALOMAR one would expect a larger loss for the former and therefore less GWPED. The opposite is observed. Regarding vertical wavelength, $\lambda_{z}$, GWPED from very small $\lambda_{z}$ (less than $1 \mathrm{~km}$ ) are Doppler-shifted into the spectral window. However, power spectral densities at these small $\lambda_{z}$ (large $k_{z}$ ) are presumably very small. In summary, the observational fact that GWPED in Kühlungsborn is larger compared to ALOMAR (independent of the filtering method) cannot easily be explained by the Doppler shifting hypothesis.

Could simple saturation considerations explain the Kühlungsborn-ALOMAR difference? As can be seen from Eq. (4) the vertical wavelength increases if the difference between the phase speed and the background wind increases. Larger vertical wavelengths are associated with more stable propagation conditions. This concept was used to derive a simple condition for gravity wave saturation applying the convective instability limit criterium (Fritts 1984). This results in a condition for the maximum zonal wind fluctuation, namely, $\left|u_{\max }^{\prime}\right|=\left|v_{\varphi, x}-\bar{u}\right|$. Applying polarization relations for $\mathrm{GW}$ results in an equivalent condition for maximum temperature fluctuations, namely,

$$
\begin{aligned}
\left|\frac{T_{\max }^{\prime}}{\bar{T}}\right| & =\frac{N^{2}}{g} \frac{m}{k_{x} \hat{\omega}}\left|\frac{\hat{\omega}^{2}-f^{2}}{N^{2}-\hat{\omega}^{2}}\right|\left|v_{\varphi, x}-\bar{u}\right| \\
& \approx \frac{N}{g}\left|v_{\varphi, x}-\bar{u}\right| \quad \text { if } \quad N \gg \hat{\omega} \gg f .
\end{aligned}
$$

If we assume, for example, $\mathrm{GW}$ with zero phase speeds (note that only GW with negative and zero phase speeds can propagate into the middle stratosphere) in a background wind of 75 and $40 \mathrm{~m} \mathrm{~s}^{-1}$ at Kühlungsborn and ALOMAR, respectively, this would allow maximum temperature fluctuations of roughly $T_{\max }^{\prime}=37 \mathrm{~K}$ and $T_{\max }^{\prime}=20 \mathrm{~K}$ at these stations. This implies that maximum temperature fluctuations according to the convective instability limit are indeed larger in Kühlungsborn compared to ALOMAR. However, the magnitude of these fluctuations is much larger compared to observations (see Fig. 3). We note that $T^{\prime}$ is significantly smaller if $\mathrm{GW}$ with large periods are considered, i.e., if $f^{2}$ can no longer be ignored relative to $\hat{\omega}^{2}$ in Eq. (6).

Another possibility is that GWs can start to dissipate well before reaching the saturation amplitude (e.g., Achatz 2007). Therefore the difference in saturation amplitudes could still play a role because GWs of the same amplitude would be "closer to saturation" at ALOMAR than at Kühlungsborn.

\section{c. ALOMAR versus Kühlungsborn: Sources?}

One could speculate that GW sources are different at both stations. Indeed, ALOMAR is located near the Scandinavian mountains, whereas there are no mountains anywhere close to Kühlungsborn. Simply speaking, this would suggest stronger GW activity at ALOMAR compared to Kühlungsborn, which, however, is not confirmed by our SABER observations. Note that mountain waves are not included in the lidar dataset.

We note that simple scenarios regarding filtering of $\mathrm{GW}$, Doppler shifting, and GW sources do not explain that $E_{\mathrm{pV}}$ is larger in Kühlungsborn compared to ALOMAR. This implies that simple GW parameterizations based on the idea of Lindzen (1981) will most likely not be able to explain the latitudinal difference of GWPED in winter. More complicated scenarios are therefore likely. For example, it is known that GW can propagate large distances (several thousand kilometers) away from their source region and they are refracted at horizontal inhomogeneities of the large-scale background (e.g., Eckermann and Vincent 1989; Alexander 1998; Sato et al. 2009; Achatz et al. 2012; Suzuki et al. 2013; Krisch et al. 2017). This implies that local tropospheric GW sources perhaps play a minor role in this context. We note that some studies have indicated stronger wave activity at the edges of the polar vortex, i.e., closer to Kühlungsborn than to ALOMAR which is presumably related to horizontal propagation of $\mathrm{GW}$ from lower latitudes toward the polar vortex (e.g., Whiteway and Carswell 1995; Whiteway and Duck 1999; Duck et al. 2001; Ern et al. 2011, 2018; Llamedo et al. 2019). Furthermore, simulations of GW have shown that a time varying background will substantially modify the propagation conditions for GW and that generation of secondary gravity waves is presumably important (see, e.g., Senf and Achatz 2011; Becker and Vadas 2018). A comprehensive discussion and explanation of the Kühlungsborn-ALOMAR difference would need sophisticated modeling including various GW sources, horizontal propagation, and a time-dependent background wind.

\section{d. Winter-summer differences}

It is generally accepted that GW activity in the middle atmosphere is stronger in winter compared to summer. This is generally confirmed by lidar and SABER observations presented in this paper (Figs. 6 and 10). Details depend on which part of the spectrum is considered. The winter/summer ratios in ERA5 and MERRA-2 very much depend on the filtering method being applied. For small periods $(\tau<8 \mathrm{~h}$, temporally filtered) winter and summer values are nearly identical, for both ERA5 and MERRA-2, and also at both stations. For unfiltered and vertically filtered data, the winter/summer ratios are larger in ERA5 (1:6) and even larger in MERRA-2 (1:10), where winter/summer ratios decrease with altitude.

The standard explanation of the fact that GWPED in winter are larger compared to summer is based on the filtering of GW by the background winds, assuming that the distribution of GW phase speeds is concentrated around $v_{\varphi, x}=0 \mathrm{~m} \mathrm{~s}^{-1}$. In winter, all GW with negative phase speeds can propagate from lower altitudes to the middle atmosphere, whereas in summer, all $\mathrm{GW}$ with negative phase speeds and some part of GW with 

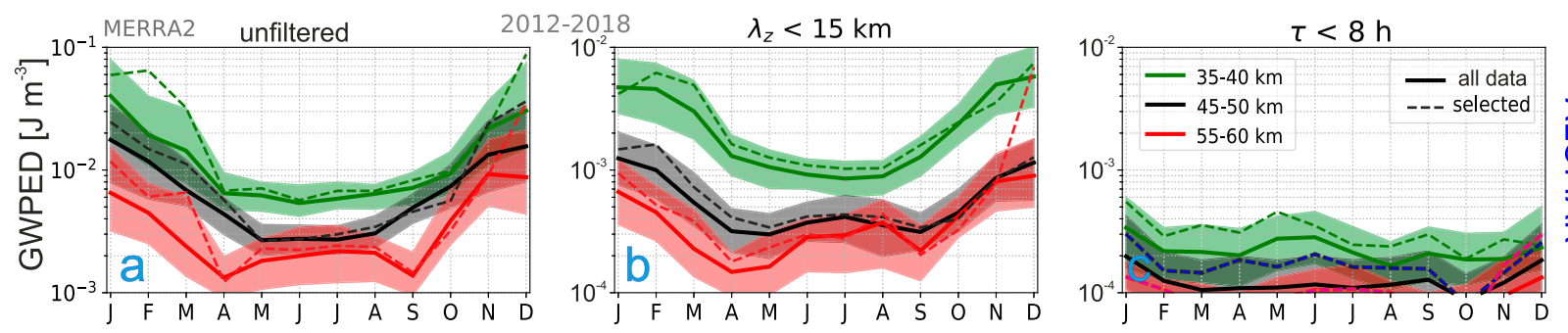

\section{$\frac{D}{O}$}
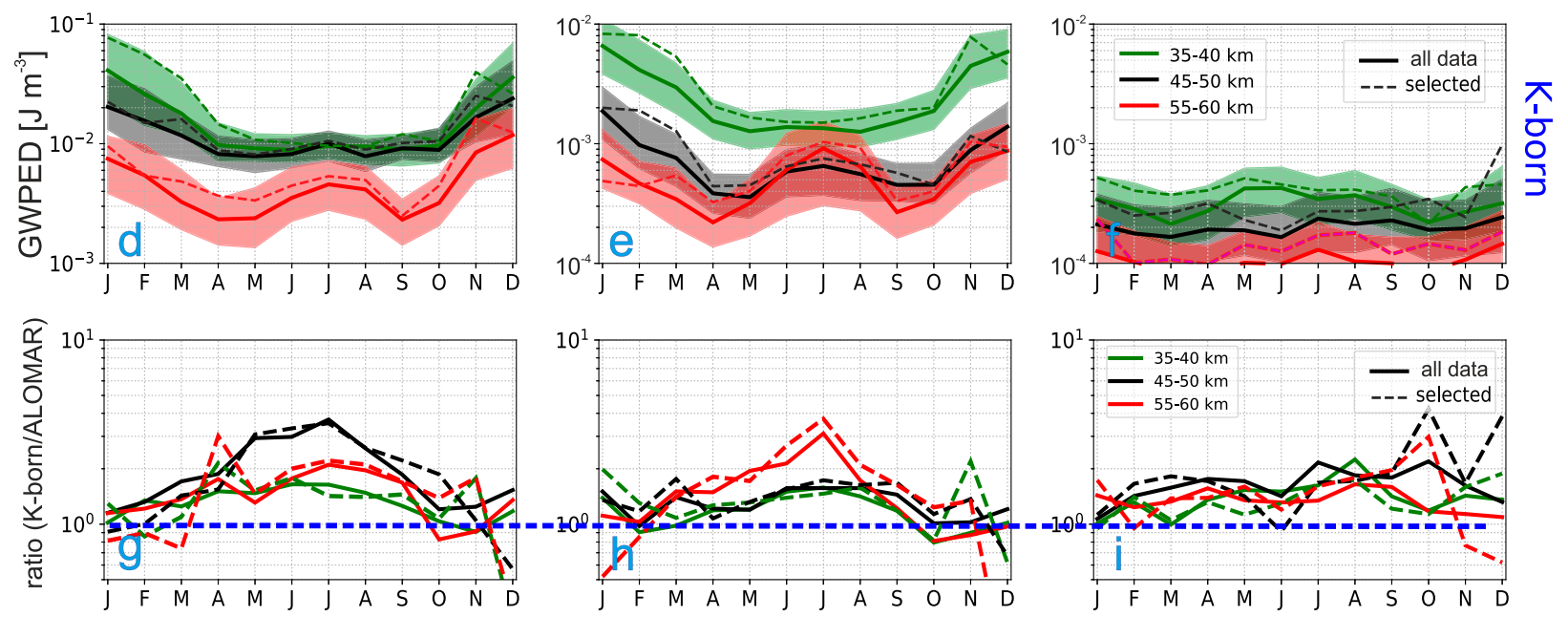

FIG. A1. Seasonal cycle of $E_{\mathrm{pV}}$ at (a)-(c) ALOMAR and (d)-(f) Kühlungsborn obtained from MERRA-2 at selected altitude ranges: 35-40 (green), 45-50 (black), and 55-60 km (red). Solid lines are obtained from 7 years (2012-18) of MERRA-2 data. Dashed lines show results for days of lidar observations. Each column shows the results for different methods used for calculation of $E_{\mathrm{pV}}$ : (left) unfiltered, (center) vertically filtered, and (right) temporally filtered. (a)-(f) Shaded regions show the standard deviations. (g)-(i) The ratio of $E_{\mathrm{pV}}$ between Kühlungsborn and ALOMAR. The blue dashed line represents a ratio of 1 . Note the different scales on the $Y$ axis in (a) and (d) vs (b), (c), (e), and (f).

positive phase speeds are absorbed. We note that our lidar observations show a relatively small winter-summer variation for $E_{\mathrm{pV}}$ (typically a factor of $\sim 1-3$ ) whereas SABER gives somewhat larger results (factor of $\sim 3-4$ ).

Also emission of gravity waves by jets and fronts can be stronger pronounced in winter (e.g., Sato and Yoshiki 2008; Plougonven and Zhang 2014; de la Cámara and Lott 2015).

\section{e. $G W$-scale height: Decrease of $E_{p V}$ with altitude}

Is the observed decrease of $E_{\mathrm{pV}}$ with altitude due to meanflow impact or due to dissipation?

A part of the winter-summer difference is presumably related to the filtering mechanism discussed above: in winter GW with westward phase speeds can undisturbedly propagate from lower altitudes to the middle mesosphere, whereas they get absorbed in summer. Due to the increase of the wind with altitude (Fig. 16), the vertical wavelengths of GWs also increase with altitude [Eq. (4)]. This leads to more stable propagation conditions in winter compared to summer. But this also removes energy from our filtered data $\left(\lambda_{z}>15 \mathrm{~km}\right)$. Thus, $H_{\mathrm{pv}}$ of the vertically filtered data will be smaller than $H_{\mathrm{pV}}$ of the unfiltered data. This is exactly what we observe at lower altitudes over Kühlungsborn (see Table 3).

Gravity waves respond to the ambient wind by changes in their wavenumber and amplitude. This leads to the expectation that the $E_{\mathrm{pV}}$ will decrease with altitude in the stratosphere. Using the midfrequency approximation (that the intrinsic frequencies are well between the Coriolis and the Brunt-Väisälä frequency) one can deduce from the vertical invariance of the vertical wave-action flux that the $E_{\mathrm{pV}}$ should be proportional to the vertical wavenumber.

Thus, changes of $E_{\mathrm{pV}}$ relative to a reference altitude $\left(z_{\mathrm{ref}}\right)$, using Eq. (4) and neglecting the variation in $N$ with height, can be written:

$$
R=\frac{E_{\mathrm{pV}}(z)}{E_{\mathrm{pV}}\left(z_{\mathrm{ref}}\right)}=\frac{\left|v_{\varphi, x}-\bar{u}\right|_{z_{\mathrm{ref}}}}{\left|v_{\varphi, x}-\bar{u}\right|_{z}}
$$

Note that here we assume that waves propagate in zonal direction. If this is not the case, the effect will be smaller and disappear if waves propagate perpendicular to the background wind. The changes of $E_{\mathrm{pV}}$ relative to the ground expected to be significant, but we used $z_{\text {ref }}=30 \mathrm{~km}$, namely, the lowest height in our study. We varied $v_{\varphi, x}$ from -20 to $+20 \mathrm{~m} \mathrm{~s}^{-1}$. Our results show that the variations of $E_{\mathrm{pV}}$ with altitude due to changes of the background winds are approximately in the range between $R=0.5$ and $R=2.0$. This is significantly smaller than the decline of $E_{\mathrm{pV}}$ with altitude as shown, for example, in Figs. 4 and 9. Thus, only a minor fraction of the observed decrease of 

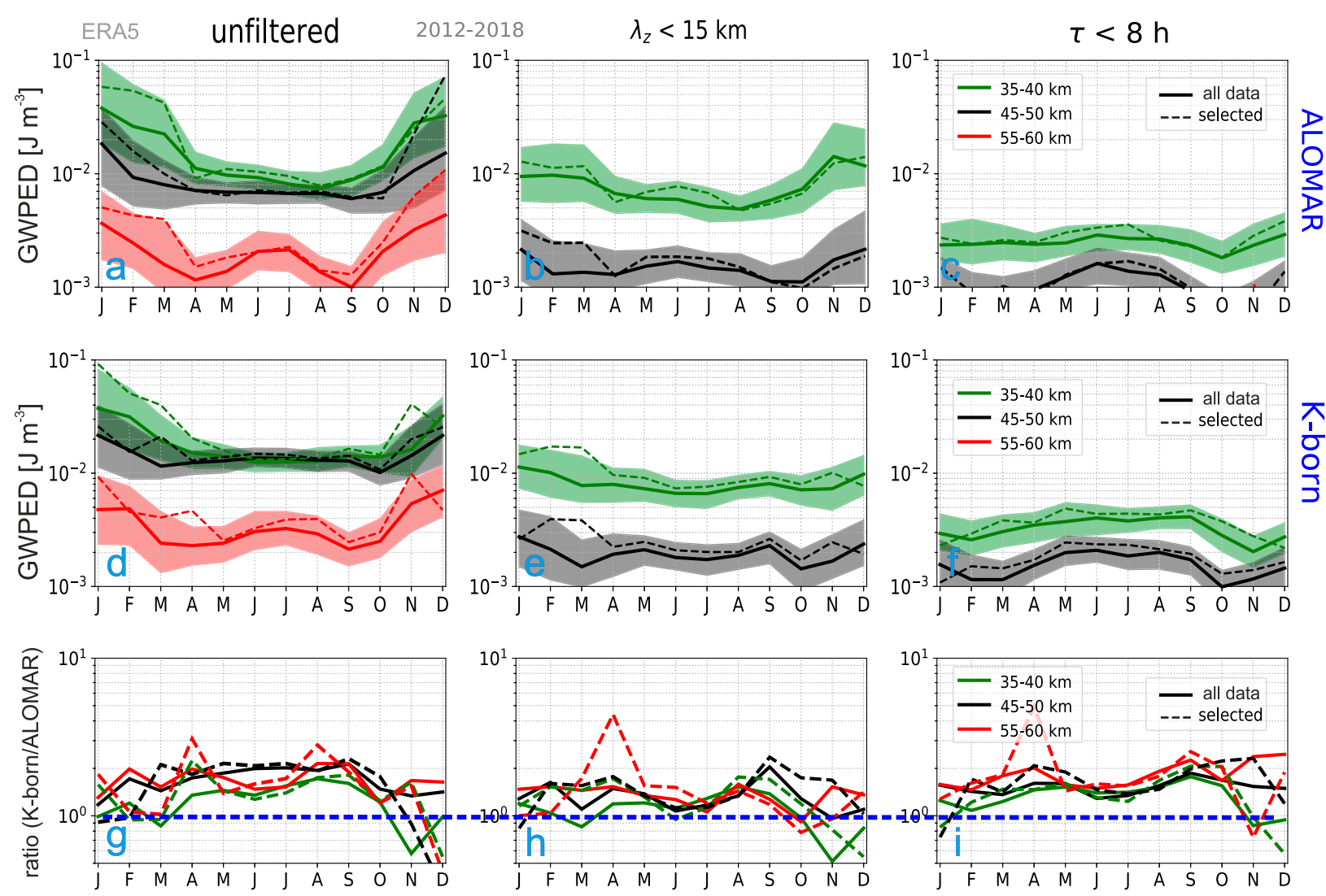

FIG. A2. As in Fig. A1, but for the seasonal cycle obtained from ERA5.

GWPED may be due to changes of $E_{\mathrm{pV}}$ even when conserving wave action.

\section{f. Increase of $E_{p V}$ above approximately $50 \mathrm{~km}$ in summer}

Interestingly, $E_{\mathrm{pV}}$ is nearly constant or even increases with height in summer for altitudes above roughly $50-55 \mathrm{~km}$ (see Fig. 13). For lidar, this feature is very pronounced at ALOMAR (all filtering methods) and to a lesser extent also in Kühlungsborn. This behavior is also seen in the SABER profiles (Fig. 9). Comparison with Fig. 16 shows that the vertical gradient of mean zonal winds also changes from negative to positive around these altitudes. It is therefore tempting to assume that dissipation ends above roughly $50-55 \mathrm{~km}$ because filtering of GW stops at these altitudes since all GW with phase speeds larger (less negative) than the minimum wind have already been absorbed at lower heights and the rest (with even smaller phase speeds) can propagate freely further upward. Certainly, this is a crude description of much more complicated processes. It is therefore not surprising, that a detailed comparison of the summer $E_{\mathrm{pV}}$ and zonal wind profiles in Figs. 13 and 16 does not agree everywhere with this simple scenario.

\section{Conclusions}

In this paper we present a climatology of GW activity based on seven years of lidar observations at two locations in the
Northern Hemisphere, namely, at $54^{\circ}$ and $69^{\circ} \mathrm{N}$. We used high resolution measurements by two ground-based RMR lidars, satellite-borne SABER observations, as well as MERRA-2 and ERA5 data. For the sake of consistency, lidar and reanalysis data were analyzed in an identical manner. SABER data were analyzed to match the lidar/reanalysis procedure as close as possible. The altitude coverage of the measurements is 30 to $70 \mathrm{~km}$. Considering sudden stratospheric warmings (SSW), we conclude that it is rather unlikely that SSW leads to a significant bias of our GWPED climatology in winter. Comparing SABER and reanalysis results from times with and without lidar observations, no significant difference is observed. We therefore conclude that the climatology derived from lidar observations is presumably representative regarding the variation of GWPED with season and altitude at both locations.

Absolute values of $E_{\mathrm{pV}}$ from SABER are very similar to vertically filtered lidar data $\left(\lambda_{z}<15 \mathrm{~km}\right)$ but are significantly larger than temporally filtered lidar data $(\tau<8 \mathrm{~h})$, and smaller than unfiltered lidar data. Absolute values of $E_{\mathrm{pV}}$ from lidar and reanalyses are similar at both stations, but only at the lowest altitudes (in case of ERA5, up to $45 \mathrm{~km}$ and for MERRA-2 close to $30 \mathrm{~km}$ ). In winter, $E_{\mathrm{pV}}$ from MERRA-2 and ERA5 are smaller by up to approximately two orders of magnitude (compared to lidar) where the difference increases with height. The situation is more complex in summer. The excessive decrease in GWPED in ERA5 can presumably be 


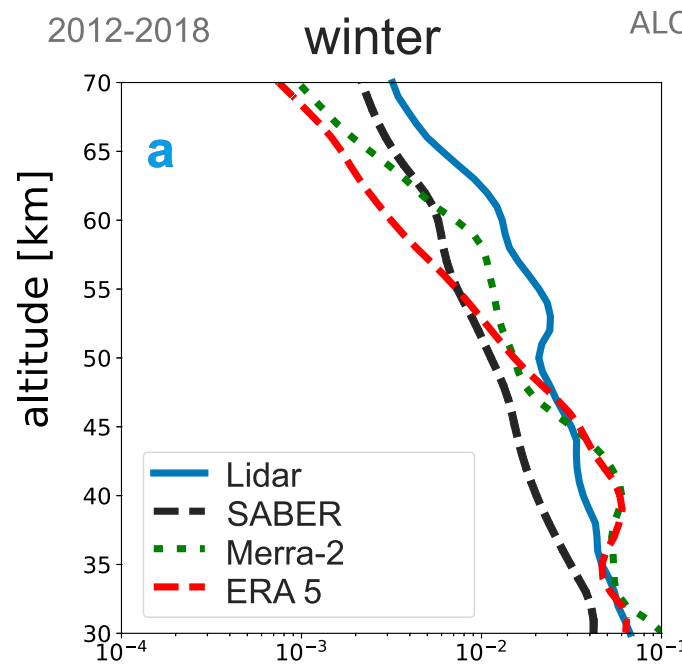

\section{ALOMAR summer}
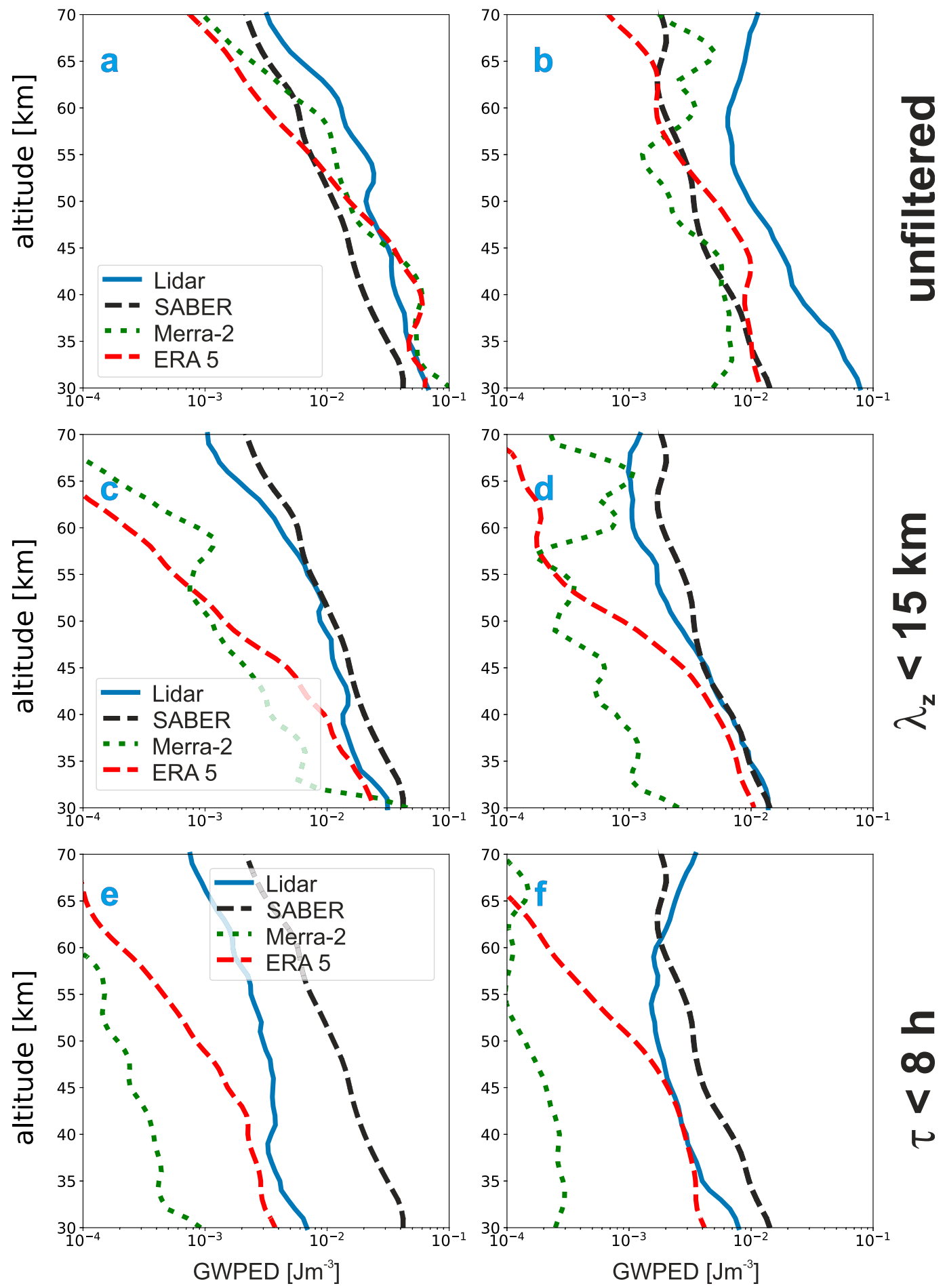

FIG. B1. Average profiles of $E_{\mathrm{pV}}$ over ALOMAR during (left) Winter (December-February) and (right) summer (June-August). Blue solid lines show lidar measurements. SABER (black dashed lines), MERRA-2 (green dotted lines), and ERA5 (red dashed lines) are limited to profiles during days of lidar operation. Results are shown for (top) unfiltered, (center) vertically filtered, and (bottom) temporally filtered data. SABER data are the same in each row and irrespective of the filtering method of the other data. 


\section{2-2018 winter}
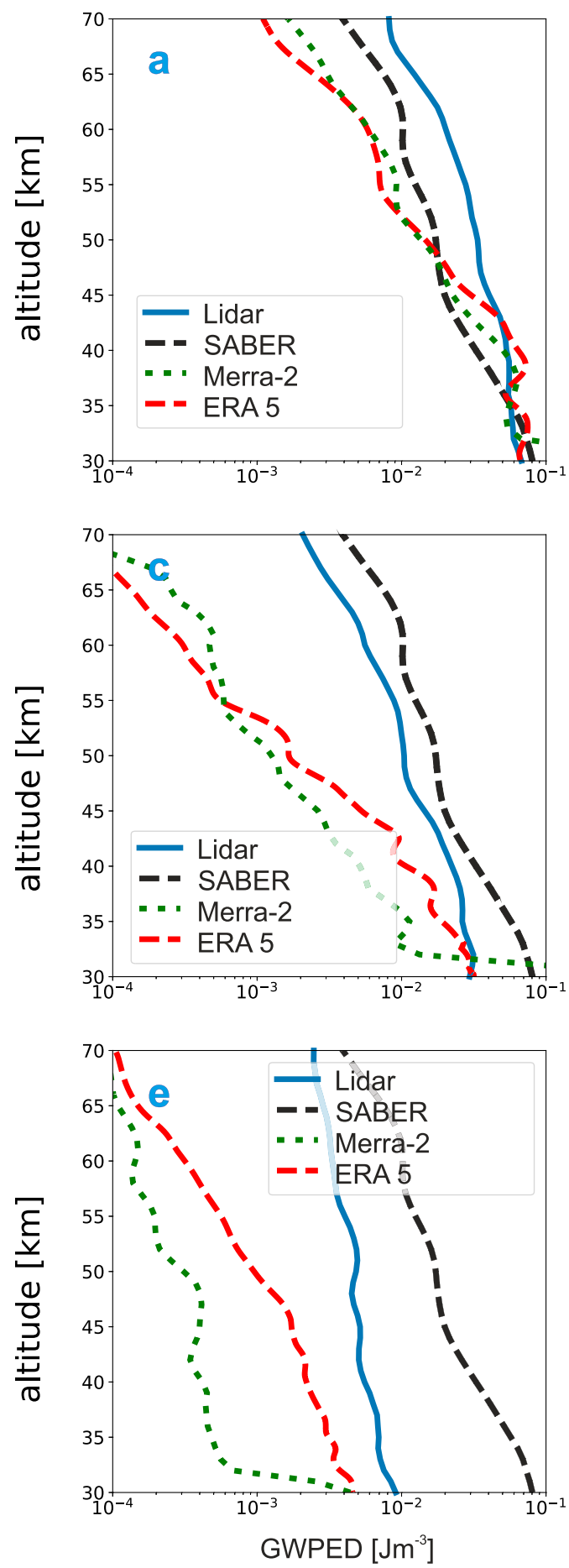

Kühlungsborn summer
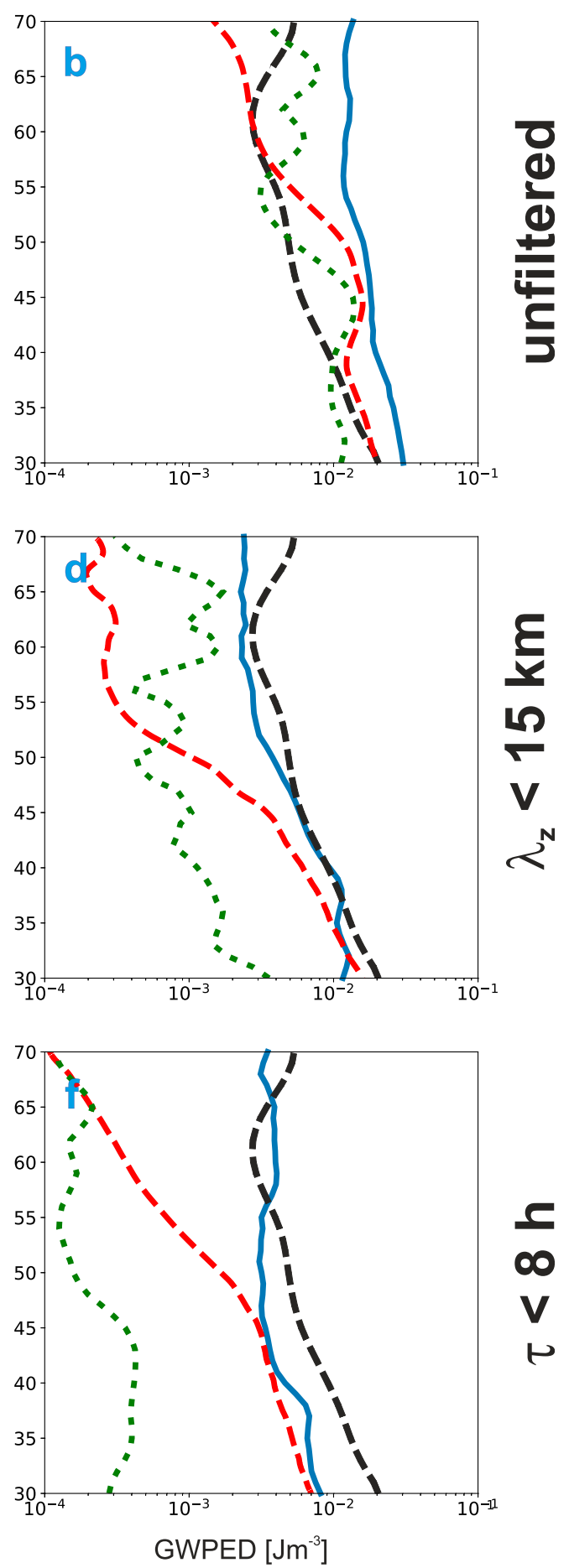

FIG. B2. As in Fig. B1, but for Kühlungsborn location.

attributed to the sponge layers, whereas MERRA-2 shows overall lower values.

A pronounced seasonal cycle is observed for $E_{\mathrm{pV}}$ in most cases at both locations, namely, Kühlungsborn $\left(54^{\circ} \mathrm{N}\right)$ and
ALOMAR $\left(69^{\circ} \mathrm{N}\right)$. For example, lidars show maxima in winter and minima in summer at both locations for both the unfiltered and the vertically filtered data. The seasonal variation from SABER is similar but with a slightly larger winter-summer 
TABLE C1. Seasonal variation of $E_{\mathrm{pV}}\left(\mathrm{J} \mathrm{m}^{-3}\right)$ for different altitude ranges $(\mathrm{km})$ measured at ALOMAR.

\begin{tabular}{cccccccccccccc}
\hline \hline Method & Altitude & Jan & Feb & Mar & Apr & May & Jun & Jul & Aug & Sep & Oct & Nov & Dec \\
\hline Unfiltered & $35-40$ & 0.0360 & 0.0234 & 0.0211 & 0.0170 & 0.0252 & 0.0251 & 0.0310 & 0.0191 & 0.0141 & 0.0222 & 0.0207 & 0.0473 \\
& $45-50$ & 0.0242 & 0.0118 & 0.0101 & 0.0071 & 0.0116 & 0.0127 & 0.0126 & 0.0098 & 0.0071 & 0.0093 & 0.0102 & 0.0214 \\
& $55-60$ & 0.0118 & 0.0084 & 0.0062 & 0.0068 & 0.0066 & 0.0074 & 0.0056 & 0.0045 & 0.0048 & 0.0115 & 0.0049 & 0.0145 \\
$\lambda_{z}<15 \mathrm{~km}$ & $35-40$ & 0.0142 & 0.0107 & 0.0116 & 0.0100 & 0.0080 & 0.0075 & 0.0062 & 0.0057 & 0.0068 & 0.0077 & 0.0141 & 0.0150 \\
& $45-50$ & 0.0084 & 0.0057 & 0.0051 & 0.0029 & 0.0033 & 0.0030 & 0.0027 & 0.0031 & 0.0026 & 0.0037 & 0.0088 & 0.0080 \\
& $55-60$ & 0.0050 & 0.0031 & 0.0019 & 0.0021 & 0.0015 & 0.0014 & 0.0012 & 0.0012 & 0.0018 & 0.0030 & 0.0030 & 0.0031 \\
$\tau<8 \mathrm{~h}$ & $35-40$ & 0.0037 & 0.0028 & 0.0053 & 0.0026 & 0.0035 & 0.0040 & 0.0044 & 0.0033 & 0.0030 & 0.0026 & 0.0018 & 0.0051 \\
& $45-50$ & 0.0034 & 0.0022 & 0.0020 & 0.0018 & 0.0020 & 0.0021 & 0.0021 & 0.0017 & 0.0015 & 0.0014 & 0.0016 & 0.0031 \\
& $55-60$ & 0.0019 & 0.0017 & 0.0017 & 0.0023 & 0.0017 & 0.0020 & 0.0018 & 0.0014 & 0.0013 & 0.0010 & 0.0018 & 0.0020 \\
\hline
\end{tabular}

variation. Regarding reanalysis data, MERRA-2 reproduces a winter maximum and summer minimum of similar magnitude compared to lidar, whereas the seasonal variation is much smaller in ERA5. The temporally filtered lidar measurements $(\tau<8 \mathrm{~h})$ do not show any clear seasonal dependence. The winter-summer variation of $E_{\mathrm{pV}}$ is quantitatively rather different compared to the variation of $E_{\mathrm{pm}}$. The latter is frequently used in the literature. We conclude that when comparing the seasonal variation of GWPED from different sources and at different locations one should carefully consider which quantity is actually discussed and if variations of the background atmosphere (density, buoyancy frequency, etc.) are carefully taken into account. A semiannual variation with a small amplitude is observed in the unfiltered data at Kühlungsborn and at ALOMAR. Such a semiannual modulation is also present in SABER and in reanalysis data.

Considering lidar measurements below $50 \mathrm{~km}$, the decrease of $E_{\mathrm{pV}}$ with height is stronger in summer than in winter, irrespective of filtering method and location. The smallest decrease of $E_{\mathrm{pV}}$ with altitude (largest-scale heights $H_{\mathrm{pV}}$ ) is observed in winter for lidar data with small periods (i.e., $\tau<$ $8 \mathrm{~h}$ ) at both stations. The conservation of wave action leads to a variation of $E_{\mathrm{pV}}$ with altitude which, however, is small compared to the observed variation of $E_{\mathrm{pV}}$. For SABER, the energy-scale heights in winter and summer are roughly the same at both stations. At higher altitudes $E_{\mathrm{pV}}$ decreases rapidly with altitude in winter but it remains nearly constant in summer, consistent with the standard scenario of GW dissipation and filtering by background winds. In more detail, $E_{\mathrm{pV}}$-scale heights changes significantly with height and depend on, for example, filtering technique. This suggests that different parts of the GW spectrum dissipate at different altitudes, which also depends on season.

The value of $E_{\mathrm{pV}}$ at Kühlungsborn $\left(54^{\circ} \mathrm{N}\right)$ is significantly larger compared to that at ALOMAR $\left(69^{\circ} \mathrm{N}\right)$. This observation is opposite to simple scenarios, which take into account the potential impact of background winds on $\mathrm{GW}$ filtering and Doppler shifts of vertical wavelengths and periods. Part of the observed latitudinal difference can be explained by modulation of GW activity by the background winds. The analysis of saturation amplitudes shows that, for waves of slow ground based phase speed that are approaching instability, the wave amplitudes will be larger in regions where the winds are larger (cf. Ern et al. 2015). Comparing lidar with SABER, we note that the difference between both stations in lidar is presumably larger compared to similar stations at other longitudes. Sophisticated modeling involving more complicated processes such as horizontal propagation of GW over large distances, GW activity related to the position of the polar vortex, and secondary wave generation is required.

In summary, this study shows that information about GW from rather different sources (lidars, satellites, reanalyses) can provide details about the complex morphology of GW in terms of variation with altitude, latitude, and season as well as the contribution of different spectral components to the overall variability. In the end, the interplay between gravity wave sources, propagation, filtering and dissipation in an altitude and time dependent background atmosphere determines

TABLE C2. Seasonal variation of $E_{\mathrm{pV}}\left(\mathrm{J} \mathrm{m}^{-3}\right)$ for different altitude ranges $(\mathrm{km})$ measured at Kühlungsborn.

\begin{tabular}{cccccccccccccc}
\hline \hline Method & Altitude & Jan & Feb & Mar & Apr & May & Jun & Jul & Aug & Sep & Oct & Nov & Dec \\
\hline Unfiltered & $35-40$ & 0.0714 & 0.0641 & 0.0503 & 0.0364 & 0.0262 & 0.0235 & 0.0262 & 0.0230 & 0.0293 & 0.0258 & 0.0438 & 0.0388 \\
& $45-50$ & 0.0402 & 0.0284 & 0.0261 & 0.0161 & 0.0105 & 0.0133 & 0.0142 & 0.0133 & 0.0133 & 0.0156 & 0.0294 & 0.0619 \\
& $55-60$ & 0.0257 & 0.0191 & 0.0160 & 0.0103 & 0.0080 & 0.0100 & 0.0098 & 0.0101 & 0.0065 & 0.0107 & 0.0357 & 0.0392 \\
$\lambda_{z}<15 \mathrm{~km}$ & $35-40$ & 0.0270 & 0.0343 & 0.0235 & 0.0190 & 0.0129 & 0.0116 & 0.0133 & 0.0112 & 0.0165 & 0.0151 & 0.0140 & 0.0155 \\
& $45-50$ & 0.0090 & 0.0140 & 0.0096 & 0.0063 & 0.0041 & 0.0040 & 0.0039 & 0.0039 & 0.0053 & 0.0057 & 0.0109 & 0.0103 \\
& $55-60$ & 0.0078 & 0.0067 & 0.0060 & 0.0037 & 0.0024 & 0.0023 & 0.0019 & 0.0021 & 0.0024 & 0.0039 & 0.0056 & 0.0093 \\
$\tau<8 \mathrm{~h}$ & $35-40$ & 0.0069 & 0.0092 & 0.0086 & 0.0099 & 0.0082 & 0.0087 & 0.0092 & 0.0065 & 0.0072 & 0.0056 & 0.0052 & 0.0088 \\
& $45-50$ & 0.0043 & 0.0058 & 0.0039 & 0.0040 & 0.0024 & 0.0034 & 0.0034 & 0.0032 & 0.0024 & 0.0024 & 0.0039 & 0.0051 \\
& $55-60$ & 0.0032 & 0.0038 & 0.0032 & 0.0028 & 0.0025 & 0.0044 & 0.0032 & 0.0038 & 0.0019 & 0.0024 & 0.0035 & 0.0069 \\
\hline
\end{tabular}




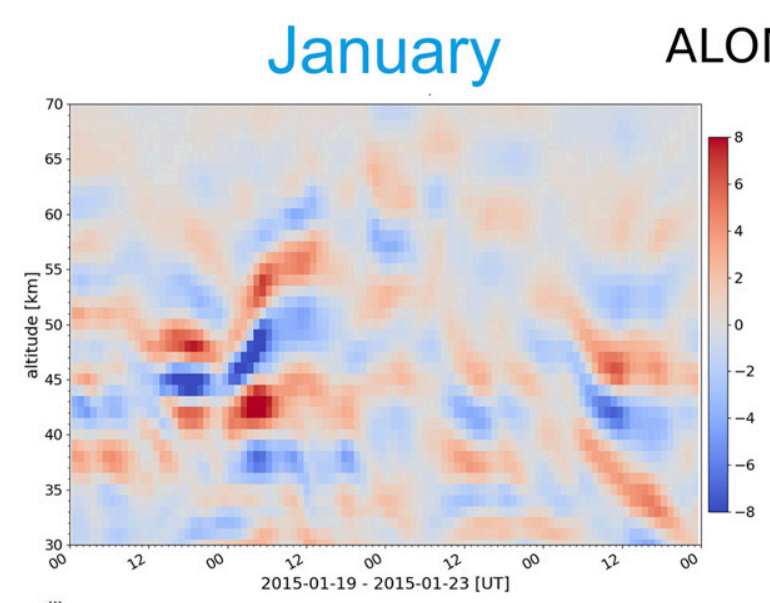

ALOMAR August
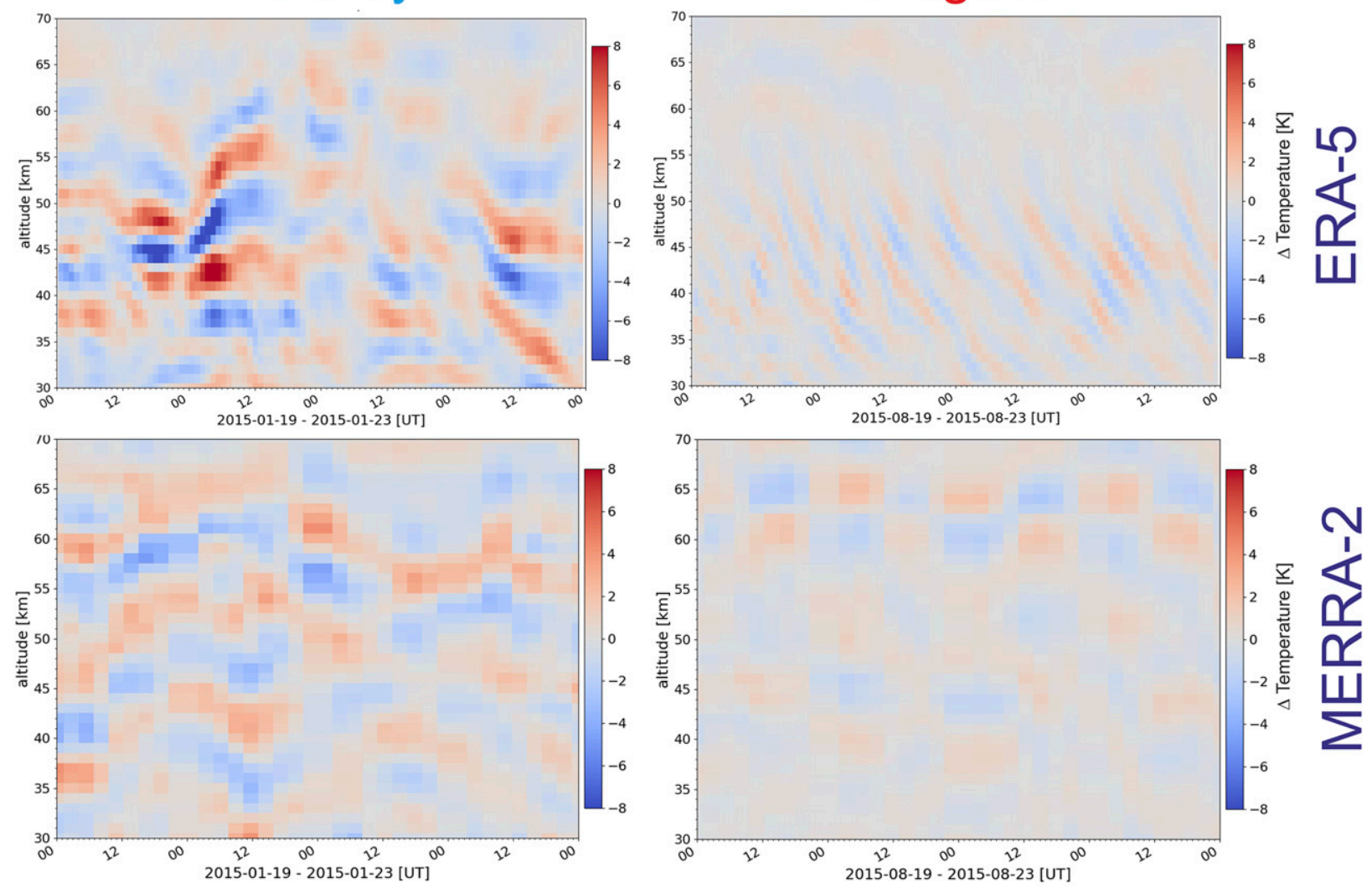

FIG. D1. Time-height cross section of vertically filtered temperature fluctuations ( $\mathrm{GW} \lambda_{z}<15 \mathrm{~km}$ ) during (left) January and (right) August at ALOMAR from (top) ERA5 and (bottom) MERRA-2 data for the same dates as in Figs. 1 and 3.

the impact of gravity waves on the general circulation as well as related effects, e.g., transport of tracers.

Acknowledgments. This paper is a contribution to the project "Mesoscale energy cascades in the lower and middle atmosphere" of the Collaborative Research Centre TRR 181 "Energy Transfer in Atmosphere and Ocean" funded by the Deutsche Forschungsgemeinschaft (DFG; German Research Foundation)_Project TRR 181/T01. The work was also supported by the DFG Projects ER 474/4-2 (MS-GWaves/SV) and LU 1174/8-1 (MS-GWaves/PACOG) which are part of the DFG researchers group FOR 1898 (MS-GWaves). We are grateful to the team of the SABER instrument for providing and maintaining this excellent dataset.

Data availability statement. SABER data are publicly available at GATS Inc. at http://saber.gats-inc.com. Data in this paper are available at ftp://ftp.iap-kborn.de/data-in-publications/ StrelnikovaJAS2020/.

\section{APPENDIX A}

\section{Climatology from ERA5 and MERRA-2}

Figures $\mathrm{A} 1$ and $\mathrm{A} 2$ show seasonal variations of $E_{p \mathrm{~V}}$ for ALOMAR and Kühlungsborn in the three altitude ranges obtained from MERRA-2 and ERA-5, respectively.

\section{APPENDIX B}

\section{Comparison of Obtained $E_{\mathrm{pv}}$ Profiles}

A summary of all the obtained $E_{\mathrm{pV}}$ profiles is shown in this appendix. Figures B1 and in Fig. B2 show results for ALOMAR and Kühlungsborn, respectively. In these figures mean profiles of observed $E_{\mathrm{pV}}$ are shown separately for winter (DJF) and summer (JJA) months. SABER profiles in these figures are the same as shown in Fig. 9 by black solid lines. These profiles were obtained as described in section $3 \mathrm{~b}$ and no additional filtering was applied. All other profiles were obtained as described in sections 1 and 2 . Rows in every figure demonstrate the methods for temperature fluctuations estimation, i.e., unfiltered, vertically filtered or temporally filtered data. SABER, MERRA-2, and ERA5 data are limited to profiles during lidar operation. This, in particular, implies that if some special event (e.g., SSW) is missing in the lidar measurements, it does not appear also in the reanalyses data. And other way around, if such an event affects the lidar measurements, it must produce the same signature in the reanalysis data.

Profiles of the unfiltered lidar measurements above approximately $50 \mathrm{~km}$ both in summer and winter reveal higher values than all other results as shown in Figs. B1a, B1b, B2a, and $\mathrm{B} 2 \mathrm{~b}$. Below $\sim 50 \mathrm{~km}$ the unfiltered lidar observations show 
better agreement with all other profiles in winter than in summer. SABER profiles demonstrate values relatively close to the lidar data only for Kühlungsborn location below $\sim 35 \mathrm{~km}$ (Fig. B2a). All other SABER data show values which are considerably lower compared to lidar measurements. This is expected because of presence of tidal signatures in the unfiltered lidar data, but not in SABER results.

Figures B1c, B1d, B2c, and B2d demonstrate analysis results for the vertically filtered data. The best agreement between lidar and SABER observations and ERA5 results was found below $\sim 45 \mathrm{~km}$ during summer months (Figs. B1d and B2d). Above this altitude a very strong decrease of $E_{\mathrm{pV}}$ in ERA5 data is obtained. In winter (Figs. B1c and B2c) lidar agrees well with SABER at ALOMAR between 40 and $55 \mathrm{~km}$ and with ERA5 at both locations only below $35 \mathrm{~km}$. SABER data in winter often reveal slightly higher values than lidar measurements. This is most likely due to the presence of GW with vertical wavelength $>15 \mathrm{~km}$ in winter. Since the discrepancy between SABER and lidar results is larger at Kühlungsborn, we can assume, that contribution of GW with larger vertical wavelengths is stronger at this location. MERRA-2 results demonstrate very low values in all altitude ranges at both locations.

Results of temporally filtered data are summarized in Figs. B1e, B1f, B2e, and B2f. Good agreement with the lidar data was found for ERA5 in summer below $45 \mathrm{~km}$. Above this height the decrease of $E_{\mathrm{pV}}$ with altitude is too strong in ERA5 results. At Kühlungsborn during wintertime (Fig. B2) the ERA5 data are lower than lidar measurements even below $45 \mathrm{~km}$. Lower values of temporally filtered $E_{\mathrm{pV}}$ estimated from MERRA-2 data can be explained by poor temporal resolution. SABER $E_{\mathrm{pV}}$ values are higher than the temporally filtered lidar data because this type of the lidar data filtering removes the most energetic part of GW spectra.

\section{APPENDIX C}

\section{Lidar Results of Seasonal Cycle of GWPED}

Tables $\mathrm{C} 1$ and $\mathrm{C} 2$ summarize results of seasonal cycle of GWPED measured by lidar.

\section{APPENDIX D}

\section{Example of Time-Height Cross Sections of Temperature Fluctuations from Reanalysis Data}

Figure D1 shows an example of time-height cross sections of temperature fluctuations obtained from ERA-5 and MERRA-2 data.

\section{REFERENCES}

Achatz, U., 2007: Gravity-wave breaking: Linear and primary nonlinear dynamics. Adv. Space Res., 40, 719-733, https:// doi.org/10.1016/j.asr.2007.03.078.

, F. Senf, and N. Grieger, 2012: Solar diurnal tides in the middle atmosphere: Interactions with the zonal-mean flow, planetary waves and gravity waves. Climate And Weather of the Sun-Earth System (CAWSES): Highlights from a Priority Program, F.-J. Lübken, Ed., Springer, 507-516, https://doi.org/ 10.1007/978-94-007-4348-9.
Alexander, M. J., 1998: Interpretations of observed climatological patterns in stratospheric gravity wave variance. J. Geophys. Res., 103, 8627-8640, https://doi.org/10.1029/97JD03325.

— , and Coauthors, 2010: Recent developments in gravity-wave effects in climate models and the global distribution of gravitywave momentum flux from observations and models. Quart. J. Roy. Meteor. Soc., 136, 1103-1124, https://doi.org/10.1002/ qj.637.

Alexander, S., and D. Murphy, 2015: The seasonal cycle of lowertropospheric gravity wave activity at Davis, Antarctica $\left(69^{\circ} \mathrm{S}\right.$, 78E). J. Atmos. Sci., 72, 1010-1021, https://doi.org/10.1175/ JAS-D-14-0171.1.

— A. R. Klekociuk, and D. J. Murphy, 2011: Rayleigh lidar observations of gravity wave activity in the winter upper stratosphere and lower mesosphere above Davis, Antarctica (69 ${ }^{\circ}$ S, $\left.78^{\circ} \mathrm{E}\right)$. J. Geophys. Res., 116, D13109, https://doi.org/ 10.1029/2010JD015164.

Allen, S. J., and R. A. Vincent, 1995: Gravity wave activity in the lower atmosphere: Seasonal and latitudinal variations. J. Geophys. Res., 100, 1327-1350, https://doi.org/10.1029/ 94JD02688.

Baumgarten, G., J. Fiedler, J. Hildebrand, and F.-J. Lübken, 2015: Inertia gravity wave in the stratosphere and mesosphere observed by Doppler wind and temperature lidar. Geophys. Res. Lett., 42, $10929-10$ 936, https://doi.org/10.1002/ 2015 GL066991.

Baumgarten, K., and G. Stober, 2019: On the evaluation of the phase relation between temperature and wind tides based on ground-based measurements and reanalysis data in the middle atmosphere. Ann. Geophys., 37, 581-602, https://doi.org/ 10.5194/angeo-37-581-2019.

_ M. Gerding, and F.-J. Lübken, 2017: Seasonal variation of gravity wave parameters using different filter methods with daylight lidar measurements at mid-latitudes. J. Geophys. Res. Atmos., 122, 2683-2695, https://doi.org/10.1002/2016JD025916.

Becker, E., and S. L. Vadas, 2018: Secondary gravity waves in the winter mesosphere: Results from a high-resolution global circulation model. J. Geophys. Res. Atmos., 123, 2605-2627, https://doi.org/10.1002/2017JD027460.

Cai, X., T. Yuan, and H. Liu, 2017: Large-scale gravity wave perturbations in the mesopause region above Northern Hemisphere midlatitudes during autumnal equinox: A joint study by the USU Na lidar and Whole Atmosphere Community Climate Model. Ann. Geophys., 35, 181-188, https://doi.org/10.5194/angeo-35181-2017.

Chen, D., C. Strube, M. Ern, P. Preusse, and M. Riese, 2019: Global analysis for periodic variations in gravity wave squared amplitudes and momentum fluxes in the middle atmosphere. Ann. Geophys., 37, 487-506, https://doi.org/10.5194/angeo-37487-2019.

Chu, X., and Coauthors, 2018: Lidar observations of stratospheric gravity waves from 2011 to 2015 at McMurdo $\left(77.84^{\circ} \mathrm{S}\right.$, $166.69^{\circ} \mathrm{E}$ ), Antarctica: 2. Potential energy densities, lognormal distributions, and seasonal variations. J. Geophys. Res. Atmos., 123, 7910-7934, https://doi.org/10.1029/2017JD027386.

Copernicus Climate Change Service, 2017: ERA5: Fifth generation of ECMWF atmospheric reanalyses of the global climate. Copernicus Climate Change Service Climate Data Store, accessed April 2020, https://cds.climate.copernicus.eu/cdsapp\#!/ home.

Davis, R. N., J. Du, A. K. Smith, W. E. Ward, and N. J. Mitchell, 2013: The diurnal and semidiurnal tides over Ascension Island $\left(8^{\circ} \mathrm{S}\right.$, $14^{\circ} \mathrm{W}$ ) and their interaction with the stratospheric quasi-biennial 
oscillation: Studies with meteor radar, ECMAM and WACCM. Atmos. Chem. Phys., 13, 9543-9564, https://doi.org/10.5194/acp13-9543-2013.

de la Cámara, A., and F. Lott, 2015: A parameterization of gravity waves emitted by fronts and jets. Geophys. Res. Lett., 42, 2071-2078, https://doi.org/10.1002/2015GL063298.

Duck, T. J., J. A. Whiteway, and A. I. Carswell, 2001: The gravity wave-Arctic stratospheric vortex interaction. J. Atmos. Sci., 58, 3581-3596, https://doi.org/10.1175/1520-0469(2001)058<3581: TGWASV $>2.0 . \mathrm{CO} ; 2$.

Eckermann, S. D., 1995a: Effect of background winds on vertical wavenumber spectra of atmospheric gravity waves. J. Geophys. Res., 100, 14 097-14 112, https://doi.org/10.1029/ 95JD00987.

_- 1995b: On the observed morphology of gravity-wave and equatorial-wave variance in the stratosphere. J. Atmos. Terr. Phys., 57, 105-134, https://doi.org/10.1016/00219169(93)E0027-7.

__ and R. A. Vincent, 1989: Falling sphere observations of anisotropic gravity wave motions in the upper stratosphere over Australia. Pure Appl. Geophys., 130, 509-532, https://doi.org/ 10.1007/BF00874472.

—, I. Hirota, and W. K. Hocking, 1995: Gravity wave and equatorial wave morphology of the stratosphere derived from long-term rocket soundings. Quart. J. Roy. Meteor. Soc., 121, 149-186, https://doi.org/10.1002/qj.49712152108.

Ehard, B., P. Achtert, and J. Gumbel, 2014: Long-term lidar observations of wintertime gravity wave activity over northern Sweden. Ann. Geophys., 32, 1395-1405, https://doi.org/10.5194/ angeo-32-1395-2014.

— , B. Kaifler, N. Kaifler, and M. Rapp, 2015: Evaluation of methods for gravity wave extraction from middle-atmospheric lidar temperature measurements. Atmos. Meas. Tech., 8, 4645-4655, https://doi.org/10.5194/amt-8-4645-2015.

Ern, M., P. Preusse, J. C. Gille, C. L. Hepplewhite, M. G. Mlynczak, J. M. Russell III, and M. Riese, 2011: Implications for atmospheric dynamics derived from global observations of gravity wave momentum flux in stratosphere and mesosphere. J. Geophys. Res., 116, D19107, https://doi.org/ 10.1029/2011JD015821.

- — - and M. Riese, 2015: Driving of the SAO by gravity waves as observed from satellite. Ann. Geophys., 33, 483-504, https://doi.org/10.5194/angeo-33-483-2015.

_- and Coauthors, 2016: Satellite observations of middle atmosphere gravity wave absolute momentum flux and of its vertical gradient during recent stratospheric warmings. Atmos. Chem. Phys., 16, 9983-10 019, https://doi.org/10.5194/acp-169983-2016.

— , Q. T. Trinh, P. Preusse, J. C. Gille, M. G. Mlynczak, J. M. Russell III, and M. Riese, 2018: GRACILE: A comprehensive climatology of atmospheric gravity wave parameters based on satellite limb soundings. Earth Syst. Sci. Data, 10, 857-892, https://doi.org/10.5194/essd-10-857-2018.

Espy, P., G. Jones, G. Swenson, J. Tang, and M. Taylor, 2004: Seasonal variations of the gravity wave momentum flux in the Antarctic mesosphere and lower thermosphere. J. Geophys. Res., 109, D23109, https://doi.org/10.1029/2003JD004446.

Fiedler, J., G. Baumgarten, U. Berger, P. Hoffmann, N. Kaifler, and F.-J. Lübken, 2011: NLC and the background atmosphere above ALOMAR. Atmos. Chem. Phys., 11, 5701-5717, https:// doi.org/10.5194/acp-11-5701-2011.

Fleming, E. L., S. Chandra, J. J. Barnett, and M. Corney, 1990: Zonal mean temperature, pressure, zonal wind and geopotential height as functions of latitude. Adv. Space Res., 10, 11-59, https:// doi.org/10.1016/0273-1177(90)90386-E.

Forbes, J. M., and D. Wu, 2006: Solar tides as revealed by measurements of mesosphere temperature by the MLS experiment on UARS. J. Atmos. Sci., 63, 1776-1797, https://doi.org/ 10.1175/JAS3724.1.

Fritts, D. C., 1984: Gravity wave saturation in the middle atmosphere: A review of theory and observations. Rev. Geophys., 22, 275-308, https://doi.org/10.1029/RG022i003p00275.

— fects in the middle atmosphere. Rev. Geophys., 41, 1003, https://doi.org/10.1029/2001RG000106.

Fujiwara, M., and Coauthors, 2017: Introduction to the SPARC reanalysis intercomparison project (S-RIP) and overview of the reanalysis systems. Atmos. Chem. Phys., 17, 1417-1452, https://doi.org/10.5194/acp-17-1417-2017.

Gan, Q., J. Du, W. E. Ward, S. R. Beagley, V. I. Fomichev, and S. Zhang, 2014: Climatology of the diurnal tides from eCMAM30 (1979 to 2010) and its comparison with SABER. Earth Planets Space, 66, 103, https://doi.org/10.1186/18805981-66-103.

Gardner, C. S., M. S. Miller, and C. H. Liu, 1989: Rayleigh lidar observations of gravity wave activity in the upper stratosphere at Urbana, Illinois. J. Atmos. Sci., 46, 1838-1854, https://doi.org/10.1175/1520-0469(1989)046<1838:RLOOGW> 2.0.CO;2.

Gerding, M., M. Kopp, J. Höffner, K. Baumgarten, and F.-J. Lübken, 2016: Mesospheric temperature soundings with the new, daylight-capable IAP RMR lidar. Atmos. Meas. Tech., 9, 3707-3715, https://doi.org/10.5194/amt-9-3707-2016.

Gill, A. E., 1982: Atmosphere-Ocean Dynamics. Academic Press, $662 \mathrm{pp}$.

Global Modeling and Assimilation Office, 2015: MERRA-2 inst3_3d_asm_nv: 3D, 3-hourly, instantaneous, modellevel, assimilation, assimilated meteorological fields, v5.12.4. GES DISC, accessed January 2020, https://doi.org/ 10.5067/WWQSXQ8IVFW8.

Hauchecorne, A., and M.-L. Chanin, 1980: Density and temperature profiles obtained by lidar between 35 and $70 \mathrm{~km}$. Geophys. Res. Lett., 7, 565-568, https://doi.org/10.1029/ GL007i008p00565.

Hersbach, H., and Coauthors, 2020: The ERA5 global reanalysis. Quart. J. Roy. Meteor. Soc., 146, 1999-2049, https://doi.org/ 10.1002/qj.3803.

Hertzog, A., G. Boccara, R. A. Vincent, F. Vial, and P. Cocquerez, 2008: Estimation of gravity wave momentum flux and phase speeds from quasi-Lagrangian stratospheric balloon flights. Part II: Results from the Vorcore campaign in Antarctica. J. Atmos. Sci., 65, 3056-3070, https://doi.org/10.1175/2008JAS2710.1.

Hirota, I., 1984: Climatology of gravity waves in the middle atmosphere. J. Atmos. Terr. Phys., 46, 767-773, https://doi.org/ 10.1016/0021-9169(84)90057-6.

Hitchman, M. H., J. C. Gille, C. D. Rodgers, and G. Brasseur, 1989: The separated polar winter stratopause: A gravity wave driven climatological feature. J. Atmos. Sci., 46, 410-422, https://doi.org/10.1175/1520-0469(1989)046<0410:TSPWSA > 2.0.CO;2.

Hoffmann, L., X. Xue, and M. J. Alexander, 2013: A global view of stratospheric gravity wave hotspots located with atmospheric infrared sounder observations. J. Geophys. Res. Atmos., 118, 416-434, https://doi.org/10.1029/2012JD018658.

_, R. Spang, A. Orr, M. J. Alexander, L. A. Holt, and O. Stein, 2017: A decadal satellite record of gravity wave activity in the 
lower stratosphere to study polar stratospheric cloud formation. Atmos. Chem. Phys., 17, 2901-2920, https://doi.org/ 10.5194/acp-17-2901-2017.

Hoffmann, P., E. Becker, W. Singer, and M. Placke, 2010: Seasonal variation of mesospheric waves at northern middle and high latitudes. J. Atmos. Sol.-Terr. Phys., 72, 1068-1079, https:// doi.org/10.1016/j.jastp.2010.07.002.

Holton, J. R., 1982: The role of gravity wave induced drag and diffusion in the momentum budget of the mesosphere. J. Atmos. Sci., 39, 791-799, https://doi.org/10.1175/15200469(1982)039<0791:TROGWI>2.0.CO;2.

Jiang, Q., J. D. Doyle, A. Reinecke, R. B. Smith, and S. D. Eckermann, 2013: A modeling study of stratospheric waves over the southern Andes and Drake Passage. J. Atmos. Sci., 70, 1668-1689, https://doi.org/10.1175/JAS-D-12-0180.1.

Kaifler, B., F.-J. Lübken, J. Höffner, R. J. Morris, and T. P. Viehl, 2015: Lidar observations of gravity wave activity in the middle atmosphere over Davis $\left(69^{\circ} \mathrm{S}, 78^{\circ} \mathrm{E}\right)$, Antarctica. J. Geophys. Res. Atmos., 120, 4506-4521, https://doi.org/ 10.1002/2014JD022879.

Kawatani, Y., T. Hirooka, K. Hamilton, A. K. Smith, and M. Fujiwara, 2020: Representation of the equatorial stratopause semiannual oscillation in global atmospheric reanalyses. Atmos. Chem. Phys., 20, 9115-9133, https://doi.org/10.5194/ acp-20-9115-2020.

Kishore, P., and Coauthors, 2006: Rayleigh lidar observations of planetary waves in the middle atmosphere over Gadanki $\left(13.5^{\circ} \mathrm{N}, 79.2^{\circ} \mathrm{E}\right)$. J. Atmos. Sol.-Terr. Phys., 68, 901-910, https://doi.org/10.1016/j.jastp.2006.01.010.

Krisch, I., and Coauthors, 2017: First tomographic observations of gravity waves by the infrared limb imager GLORIA. Atmos. Chem. Phys., 17, 14 937-14 953, https://doi.org/10.5194/acp-1714937-2017.

Langenbach, A., G. Baumgarten, J. Fiedler, F.-J. Lübken, C. von Savigny, and J. Zalach, 2019: Year-round stratospheric aerosol backscatter ratios calculated from lidar measurements above northern Norway. Atmos. Meas. Tech., 2019, 4065-4076, https://doi.org/10.5194/amt-12-4065-2019.

Lindzen, R. S., 1981: Turbulence and stress owing to gravity wave and tidal breakdown. J. Geophys. Res., 86, 9707-9714, https:// doi.org/10.1029/JC086iC10p09707.

Llamedo, P., and Coauthors, 2019: 11 years of Rayleigh lidar observations of gravity wave activity above the southern tip of South America. J. Geophys. Res. Atmos., 124, 451-467, https:// doi.org/10.1029/2018JD028673.

Lübken, F.-J., 1999: Thermal structure of the Arctic summer mesosphere. J. Geophys. Res., 104, 9135-9149, https://doi.org/ 10.1029/1999JD900076.

Mitchell, N., and C. Beldon, 2009: Gravity waves in the mesopause region observed by meteor radar: 1 . A simple measurement technique. J. Atmos. Sol.-Terr. Phys., 71, 866-874, https:// doi.org/10.1016/j.jastp.2009.03.011.

Mlynczak, M. G., 1997: Energetics of the mesosphere and lower thermosphere and the SABER experiment. Adv. Space Res., 20, 1177-1183, https://doi.org/10.1016/S0273-1177(97)00769-2.

Nappo, C., 2002: An Introduction to Atmospheric Gravity Waves. International Geophysics Series, Vol. 85, Elsevier Science, $276 \mathrm{pp}$.

Pancheva, D., and P. Mukhtarov, 2011: Atmospheric tides and planetary waves: Recent progress based on SABER/TIMED. Aeronomy of the Earth's Atmosphere and Ionosphere, IAGA Special Sopron Book Series, Vol. 2, Springer, 19-56, https:// doi.org/10.1007/978-94-007-0326-1_2.
Picone, J. M., A. E. Hedin, D. P. Drob, and A. C. Aikin, 2002: NRLMSISE-00 empirical model of the atmosphere: Statistical comparisons and scientific issues. J. Geophys. Res., 107, 1468, https://doi.org/10.1029/2002JA009430.

Plougonven, R., and F. Zhang, 2014: Internal gravity waves from atmospheric jets and fronts. Rev. Geophys., 52, 33-76, https:// doi.org/10.1002/2012RG000419.

Polichtchouk, I., R. Hogan, T. Shepherd, P. Bechtold, T. Stockdale, S. Malardel, S.-J. Lock, and L. Magnusson, 2017: What influences the middle atmosphere circulation in the IFS? ECMWF Tech. Memo. 809, 50 pp., https://doi.org/10.21957/mfsnfv15o.

Preusse, P., A. Dörnbrack, S. D. Eckermann, M. Riese, B. Schaeler, J. T. Bacmeister, D. Broutman, and K. U. Grossmann, 2002: Space-based measurements of stratospheric mountain waves by CRISTA 1 . Sensitivity, analysis method, and a case study. J. Geophys. Res., 107, 8178, https://doi.org/ 10.1029/2001JD000699.

—_ S. D. Eckermann, and M. Ern, 2008: Transparency of the atmosphere to short horizontal wavelength gravity waves. J. Geophys. Res., 113, D24104, https://doi.org/10.1029/ 2007JD009682.

Rauthe, M., M. Gerding, J. Höffner, and F.-J. Lübken, 2006: Lidar temperature measurements of gravity waves over Kühlungsborn $\left(54^{\circ} \mathrm{N}\right)$ from 1 to $105 \mathrm{~km}$ : A winter-summer comparison. J. Geophys. Res., 111, D24108, https://doi.org/ 10.1029/2006JD007354.

-, _, and F.-J. Lübken, 2008: Seasonal changes in gravity wave activity measured by lidars at mid-latitudes. Atmos. Chem. Phys., 8, 6775-6787, https://doi.org/10.5194/acp-8-67752008.

Remsberg, E. E., and Coauthors, 2008: Assessment of the quality of the version 1.07 temperature-versus-pressure profiles of the middle atmosphere from TIMED/SABER. J. Geophys. Res., 113, D17101, https://doi.org/10.1029/2008JD010013.

Russell, J. M., M. G. Mlynczak, L. L. Gordley, J. J. Tansock, and R. W. Esplin, 1999: Overview of the SABER experiment and preliminary calibration results. Proc. SPIE, 3756, https:// doi.org/10.1117/12.366382.

Sato, K., and M. Yoshiki, 2008: Gravity wave generation around the polar vortex in the stratosphere revealed by 3-hourly radiosonde observations at Syowa Station. J. Atmos. Sci., 65, 3719-3735, https://doi.org/10.1175/2008JAS2539.1.

_- S. Watanabe, Y. Kawatani, Y. Tomikawa, K. Miyazaki, and M. Takahashi, 2009: On the origins of mesospheric gravity waves. Geophys. Res. Lett., 36, L19801, https://doi.org/10.1029/ 2009GL039908.

Schöch, A., G. Baumgarten, and J. Fiedler, 2008: Polar middle atmosphere temperature climatology from Rayleigh lidar measurements at ALOMAR $\left(69^{\circ} \mathrm{N}\right)$. Ann. Geophys., 26, 1681-1698, https://doi.org/10.5194/angeo-26-1681-2008.

Senf, F., and U. Achatz, 2011: On the impact of middle-atmosphere thermal tides on the propagation and dissipation of gravity waves. J. Geophys. Res., 116, D24110, https://doi.org/10.1029/ 2011JD015794.

Stober, G., and Coauthors, 2021: Seasonal evolution of winds, atmospheric tides and Reynolds stress components in the Southern Hemisphere mesosphere/lower thermosphere in 2019. Ann. Geophys., 39, 1-29, https://doi.org/10.5194/angeo39-1-2021.

Strelnikova, I., G. Baumgarten, and F.-J. Lübken, 2020: Advanced hodograph-based analysis technique to derive gravity-wave parameters from lidar observations. Atmos. Meas. Tech., 13, 479-499, https://doi.org/10.5194/amt-13-479-2020. 
Suzuki, S., F.-J. Lübken, G. Baumgarten, N. Kaifler, R. Eixmann, B. P. Williams, and T. Nakamura, 2013: Vertical propagation of a mesoscale gravity wave from the lower to the upper atmosphere. J. Atmos. Sol.-Terr. Phys., 97, 29-36, https:// doi.org/10.1016/j.jastp.2013.01.012.

Trinh, Q. T., M. Ern, E. Doornbos, P. Preusse, and M. Riese, 2018: Satellite observations of middle atmosphere-thermosphere vertical coupling by gravity waves. Ann. Geophys., 36, 425-444, https://doi.org/10.5194/angeo-36-425-2018.

Tsuda, T., Y. Murayama, T. Nakamura, R. Vincent, A. Manson, C. Meek, and R. Wilson, 1994: Variations of the gravity wave characteristics with height, season and latitude revealed by comparative observations. J. Atmos. Terr. Phys., 56, 555-568, https://doi.org/10.1016/0021-9169(94)90097-3.

—, M. Nishida, C. Rocken, and R. H. Ware, 2000: A global morphology of gravity wave activity in the stratosphere revealed by the GPS occultation data (GPS/MET). J. Geophys. Res., 105, 7257-7273, https://doi.org/10.1029/1999JD901005.

von Zahn, U., and Coauthors, 2000: The ALOMAR Rayleigh/Mie/ Raman lidar: Objectives, configuration, and performance. Ann. Geophys., 18, 815-833, https://doi.org/10.1007/s00585000-0815-2.

Wang, L., D. C. Fritts, B. P. Williams, R. A. Goldberg, F. J. Schmidlin, and U. Blum, 2006: Gravity waves in the middle atmosphere during the MaCWAVE winter campaign: Evidence of mountain wave critical level encounters. Ann. Geophys., 24, 1209-1226, https://doi.org/10.5194/angeo-241209-2006.

Whiteway, J. A., and A. I. Carswell, 1995: Lidar observations of gravity wave activity in the upper stratosphere over Toronto. J. Geophys. Res., 100, 14113-14 124, https://doi.org/10.1029/ 95JD00511.

—_, and T. J. Duck, 1999: Enhanced Arctic stratospheric gravity wave activity above a tropospheric jet. Geophys. Res. Lett., 26, 2453-2456, https://doi.org/10.1029/1999GL900548.

Wilson, R., M. L. Chanin, and A. Hauchecorne, 1991: Gravity waves in the middle atmosphere observed by Rayleigh lidar: 2 . Climatology. J. Geophys. Res., 96, 5169-5183, https://doi.org/ 10.1029/90JD02610.

Yee, J.-H., E. R. Talaat, A. B. Christensen, T. L. Killeen, J. M. Russell, and T. N. Woods, 2003: TIMED instruments. Johns Hopkins APL Tech. Dig., 24, 156-164.

Zhao, J., and Coauthors, 2017: Lidar observations of stratospheric gravity waves from 2011 to 2015 at McMurdo $\left(77.84^{\circ} \mathrm{s}, 166.69^{\circ} \mathrm{e}\right)$, Antarctica: 1 . Vertical wavelengths, periods, and frequency and vertical wave number spectra. J. Geophys. Res. Atmos., 122, 5041-5062, https://doi.org/ 10.1002/2016JD026368. 